\title{
Epigenetic effects on yeast transcription caused by mutations in an actin-related protein present in the nucleus
}

\author{
Yi Wei Jiang and David J. Stillman' \\ Division of Molecular Biology and Genetics, Department of Oncological Sciences, Huntsman Cancer Institute, University of \\ Utah Health Sciences Center, Salt Lake City, Utah 84132 USA
}

\begin{abstract}
Gene inactivation can result when a $\delta$ element of the Ty1 transposon inserted into the yeast HIS4 promoter (his4-9128) alters the transcription initiation site. Previous work has identified mutations that suppress this transcriptional defect by restoring the transcription start site to the native position, and these mutations have been implicated in transcriptional regulation and chromatin structure. We show that in a sin 4 mutant such suppression is incompletely penetrant, such that genetically identical yeast cells (sin4 his4-9128) show either of two distinct phenotypic states, $\mathrm{His}^{+}$or $\mathrm{His}^{-}$. To study this type of potential epigenetic control of gene expression, we constructed a strain with ADE2 expression under the control of the his4-9128 promoter, as colony color provides a convenient assay for $A D E 2$ expression. We isolated mutations in the ACT3 gene that show variegated expression of this $A D E 2$ reporter. The act 3 his46-ADE2 colonies display both white and red sectors, showing that the two different phenotypes are possible in a single colony. The two phenotypic states can be inherited during clonal growth, yet are reversible. Analysis of RNA isolated from individual colonies of either red or white color demonstrates that it is the state of the promoter, as either On or Off, that is inherited and is responsible for the colony color. An act 3 mutation also affects expression of the HIS4 and LYS2 genes; thus, Act $3 p$ is not a $\delta$ element-specific transcriptional regulator. Immunofluorescence microscopy experiments demonstrate that the Act3p protein is present in the nucleus. Act3p shows clear homology to actin, and possible roles for an actin-related protein in transcription are discussed.
\end{abstract}

[Key Words: Yeast transcription; actin-related protein; SIN4; Ty1 transposon; ACT3]

Received July 27, 1995; revised version accepted January 23, 1996.

Epigenetic control of gene expression refers to inheritance of a phenotypic state that is not dependent strictly on genotype. Epigenetic phenomena have been described in many experimental situations, including variegated expression of nuclear genes. Variegation in a gene's expression indicates that its promoter is either On or completely Off and that these distinct states are maintained stably through DNA replication and mitotic division. These states are completely reversible, but switches are rare during any specific cell division.

A classic example of epigenetic control of gene expression is position effect variegation (PEV) in Drosophila melanogaster (Henikoff 1994; Karpen 1994). PEV usually results from translocations that place a gene adjacent to heterochromatin. Gene inactivation is believed to result from the spreading of the transcriptionally repressive heterochromatic state along the chromosome. The chromatin structure, either heterochromatic or euchromatic, is heritable, and thus the transcriptional state of a gene is clonally propagated. Whether a gene is inactivated or not depends on whether the gene becomes heterochromatic.

${ }^{1}$ Corresponding author.
This variability in the extent of heterochromatin spreading, combined with the clonal propagation of the chromatin state, produces a variegated phenotype.

Position effects also result when genes are placed near telomeres in Saccharomyces cerevisiae (Gottschling et al. 1990) or near centromeres in Schizosaccharomyces pombe (Allshire et al. 1994; Steiner and Clarke 1994). In $S$. cerevisiae, the silent mating type loci $H M L$ and $H M R$ also display heritable, but reversible, repression (Pillus and Rine 1989). Genetic analysis has demonstrated that telomere position effect and repression of the silent mating type loci both require the SIR genes (Aparicio et al. 1991). The Raplp DNA-binding protein binds to both telomeres and to the $H M$ silencers, the cis-acting elements required for $H M L$ and $H M R$ repression. Sir3p and Sir $4 \mathrm{p}$ proteins can bind to Raplp, and it is believed that this interaction nucleates the formation of heterochromatin (Moretti et al. 1994; Hecht et al. 1995). Stretches of telomeric DNA (Raplp-binding sites) can be placed at various chromosomal locations besides telomeres and cause repression, and the SIR genes are required for this repression (Stavenhagen and Zakian 1994).

$S$. cerevisiae contains a retrovirus-like transposable el- 
ement, Tyl (Boeke and Sandmeyer 1991). It has two long terminal repeats ( $\delta$ elements) that contain promoter elements. Tyl element transposition into the HIS4 gene can result in inactivation of the gene /Chaleff and Fink 1980; Farabaugh and Fink 1980; Roeder and Fink 1980). Homologous recombination can occur between the two long terminal repeats, resulting in loss of the body of Tyl, such that only one terminal $\delta$ element remains. Figure 1 shows the his $4-912 \delta$ allele resulting from Tyl transposition followed by $\delta-\delta$ recombination. The $\delta$ element in his $4-912 \delta$ is located 97 bp upstream of the HIS4 transcription start site, between the HIS4 upstream promoter elements and the TATA box. Transcription starts exclusively from the $\delta$ element TATA box, but this transcript is not translated to produce functional His $4 \mathrm{p}$ protein and thus the cells with the his4-9128 allele are histidine auxotrophs.

Extragenic suppressor mutations that suppress the $\mathrm{His}^{-}$phenotype have been isolated in strains carrying the his4-9128 allele (Simchen et al. 1984; Winston et al. 1984). Mutations in SPT (Suppressor of Ty) genes overcome the transcriptional defect caused by the $\delta$ element insertion (Silverman and Fink 1984; Clark-Adams and Winston 1987). In strains with mutations in these SPT genes, transcripts initiating at the normal HIS4 mRNA start site are produced, and these transcripts can be used as templates to produce His $4 p$, suppressing the His ${ }^{-}$ phenotype. These studies have identified many novel transcriptional regulators, including SPT15 /encoding the TATA-binding factor), SPT11 and SPT12 (histone genes), SPT2 (an HMG-like protein), and other SPT genes implicated in chromatin structure (Roeder et al. 1985; Clark-Adams et al. 1988; Eisenmann et al. 1989; Swanson and Winston 1992).

In this report we demonstrate that in some mutants phenotypic suppression of $\delta$-element-inactivated genes occurs in only a fraction of the population of genetically identical cells. For example, only a fraction of $\sin 4$ cells with a his $4-912 \delta$ reporter are $\mathrm{His}^{+}$, indicating that gene reactivation may be epigenetically controlled. We used an $A D E 2$ reporter gene under the control of the his4-9128 promoter to screen for new mutations that cause a variegated phenotype. We identified mutations in ACT3, which encodes an actin-related protein, that cause epigenetic control of gene expression. Our results suggest that this actin-related protein functions at the level of transcription.

\section{Results}

Incomplete suppression of $\delta$ insertion by $a \sin 4$ mutation

The yeast SIN4 gene is required for the transcriptional repression of some genes, such as $H O$ and $I M E 1$, yet SIN4 also is required for the full activation of other genes, including CTS1, MAT 2 , and HIS4 (Jiang and Stillman 1992, 1995; Covitz et al. 1994). A number of phenotypes displayed by a sin 4 mutant are also seen in strains with histone mutations, suggesting that the effects of the $\sin 4$ mutation are mediated via chromatin structure (Jiang and Stillman 1992). These phenotypes include transcriptional activation of promoters lacking upstream activating sequence (UAS) elements, altered linking number of circular DNA molecules, and suppression of the histidine auxotrophy associated with the his4-912 $\delta$ allele. However, a careful examination of the phenotype of a $\sin 4$ his $4-912 \delta$ strain reveals that the suppression by $\sin 4$ is not complete (Fig. 2). Cells from strains with the his4-912 8 allele were suspended in wa-
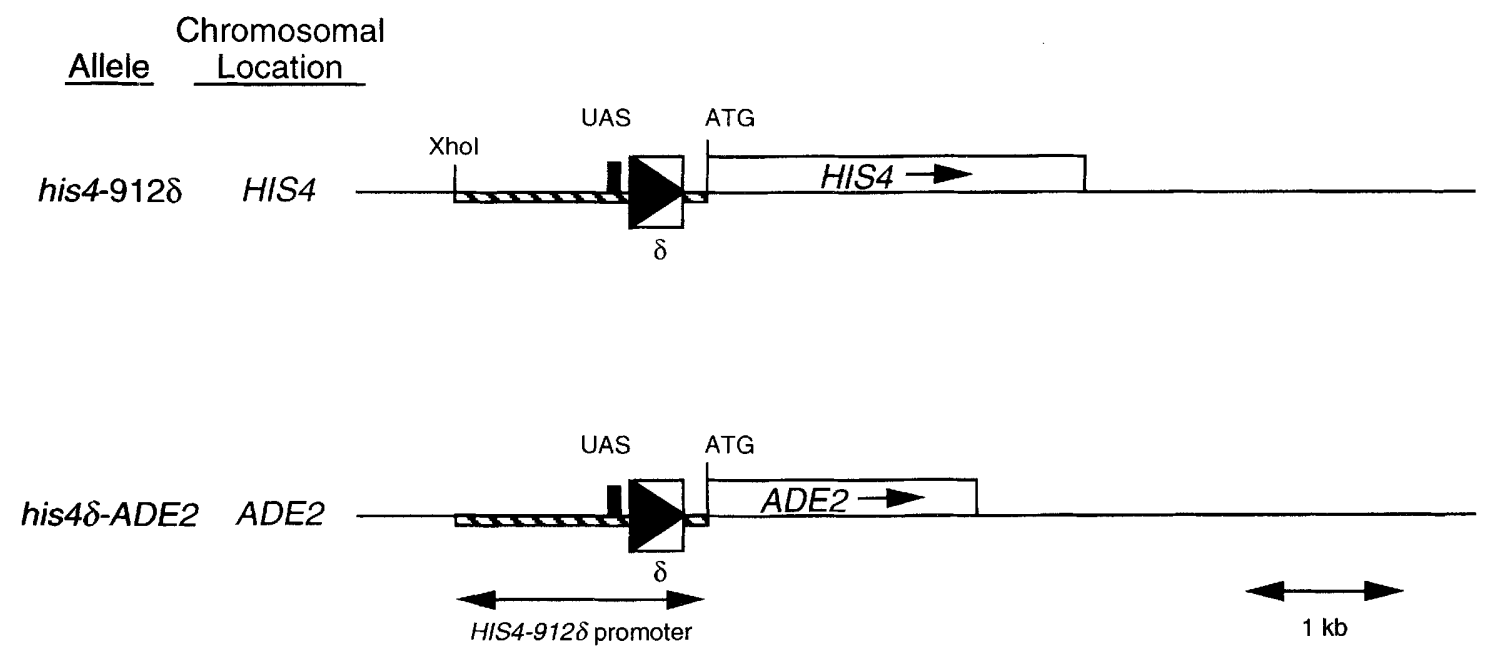

Figure 1. Structure of the alleles containing $\delta$ insertions used in this study. The 334-bp $\delta$ element is inserted $162 \mathrm{bp}$ upstream from the initiating ATG of HIS4 in the his4-918 allele (Farabaugh and Fink 1980). The his $4 \delta-A D E 2$ allele contains $1.6 \mathrm{~kb}$ from the his4-912 $\delta$ promoter that replaced the $A D E 2$ promoter. The arrow indicates the direction of transcription. UAS identifies the upstream activation sequence. The crosshatched region indicates the region from the his4-912 $\delta$ promoter that was used in the construction of the his $4 \delta-A D E 2$ allele. 


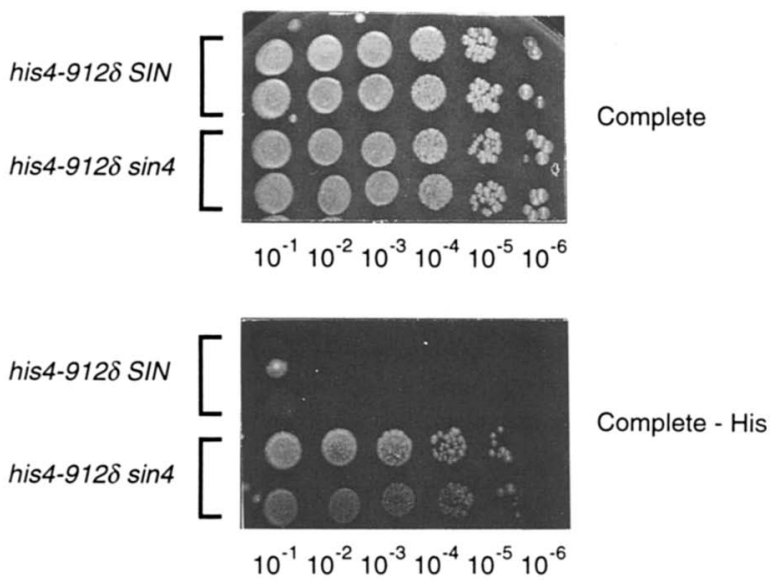

Fraction of his $4-912 \delta \sin 4$ cells that are $\mathrm{His}^{+}$

$\begin{array}{ll}\text { Experiment 1 } & 10 \% \pm 2 \\ \text { Experiment 2 } & 14 \% \pm 8 \\ \text { Experiment } 3 & 8 \% \pm 3\end{array}$

Figure 2. Incomplete suppression of his4-9128. FY56 (his4$912 \delta S I N$ ) and DY2081 (his4-9128 $\sin 4$ ) were first grown on YEPD plates. Two single colonies from each plate were suspended in $200 \mu 1$ of sterile water, 10-fold dilutions were prepared, and $10 \mu \mathrm{l}$ from each series was spotted onto SC (complete) and SC-His plates. Cells were incubated at $30^{\circ} \mathrm{C}$ for 14 days before being photographed. The fractions of his $4-912 \delta \sin 4$ cells that formed $\mathrm{His}^{+}$colonies in three separate experiment are shown.

ter, serially diluted, and tested for the ability to form colonies on plates lacking histidine. A wild-type $\left(S I N^{+}\right)$ strain carrying his4-9128 cannot form colonies, as the mutant promoter does not express an mRNA that templates for functional His $4 p$. The $\sin 4$ his $4-912 \delta$ strain can form colonies in the absence of histidine; however, only $\sim 10 \%$ of the cells spotted are capable of doing so, and a longer incubation time does not increase this fraction. We conclude that suppression of his4-912 $\delta$ by $\sin 4$ is incomplete, with distinct phenotypes, $\mathrm{His}^{+}$and $\mathrm{His}^{-}$, displayed by cells with the identical genotype. This phenomenon suggests epigenetic control.

\section{Visual screen for variegated phenotype}

Gottschling et al. (1990) used the yeast $A D E 2$ gene as a reporter to visualize the epigenetic control resulting from placing a gene near a telomere. This reporter system takes advantage of the $A D E 2$-dependent colony color, as ade2 mutants form red colonies and wild-type cells form white colonies. Differential expression from the $A D E 2$ gene gives rise to colonies with differently colored sectors. We decided to use this red/white sectoring assay to further investigate the notion that the incomplete penetrance in suppression at the his4-912 $\delta$ promoter by $\sin 4$ or some other mutations is epigenetic control of gene expression. We constructed a his4-9128$A D E 2$ reporter gene (hereafter referred to as his $4 \delta-A D E 2$ ) by placing the $A D E 2$ gene under the control of the his4$912 \delta$ promoter (Fig. 1). The his $4 \delta-A D E 2$ reporter was placed at the $A D E 2$ locus by integrative gene replacement, and the resulting strain is $\mathrm{Ade}^{-}$and forms red colonies. A $\sin 4$ mutation does not suppress the adenine auxotrophy, as a $\sin 4$ his $4 \delta-A D E 2$ strain is $\mathrm{Ade}^{-}$. It is possible that more $A D E 2$ gene product is required for prototrophy than for the HIS4 gene product, or that the genes differ in translational efficiency or protein stability. The $\sin 4$ his $4 \delta-A D E 2$ colonies are uniformly red, and thus do not display a variegated phenotype.

We screened for mutations that suppress the Ade ${ }^{-}$defect of the his $4 \delta-A D E 2$ reporter, in the hope of finding mutations that cause visibly variegated expression of his $4 \delta-A D E 2$. Spontaneous mutants that conferred an $\mathrm{Ade}^{+}$phenotype to a strain with the his $4 \delta-A D E 2$ reporter were isolated as described in Materials and methods. After being sorted into complementation groups, each mutant strain was screened for a sectoring phenotype by examining colonies grown on a medium containing a limited amount of adenine. Colonies with white and red sectors, suggesting clones of cells where the his $4 \delta-A D E 2$ gene is On or Off, respectively, possess a variegated phenotype.

As shown in Table $1,>80 \%$ of the mutant alleles are members of a single complementation group. The mutant hunt was conducted in two strains, one MATa and one $M A T \alpha$, and a similar fraction of group I mutants

Table 1. Complementation groups

\begin{tabular}{lcllccccc}
\hline Group & No. of isolates & Gene & Ade & Sectors & His & Lys & Growth & $37^{\circ} \mathrm{C}^{\mathrm{a}}$ \\
\hline I & $\sim 640$ & MOT1 & + & no & + & - & slow \\
II & 67 & SPT6 & + & no & + & + & slow \\
III & 23 & SPT5 & + & no & + & + & ts \\
IV & 32 & SPT2 & + & no & + & + & now \\
V & 6 & ACT3 & + & yes & + & - & growth \\
& & & & slow & growth \\
\hline
\end{tabular}

The first five complementation groups are listed. In addition, there are 18 additional mutants with a sectoring phenotype that do not complement group I-V.

${ }^{a}$ (ts) Temperature sensitive. 
were isolated from each strain; we therefore believe that these mutants are independent and not attributable to events that occurred during the growth of the cultures. These group I mutants grow slowly, and complementation was used to identify plasmids that restore normal growth. Molecular and genetic analyses demonstrated that these plasmids contain the MOT1 gene (data not shown). MOT1 was originally identified by mutations that led to constitutive expression of pheromone-responsive genes (Davis et al. 1992) and the POL1 DNA polymerase $\alpha$ gene (Piatti et al. 1992). MOT1 was later shown to encode a protein that inhibits TBP binding to DNA by an ATP-dependent mechanism (Auble et al. 1994) and to be the same as the TBP-binding factor TAF170 (Poon et al. 1994).

The yeast LYS2 gene has also been used in studies of suppression of genes inactivated by insertion of a $\delta$ element (Simchen et al. 1984). Strains with the 1ys2-1288 allele are lysine auxotrophs, and the previously described

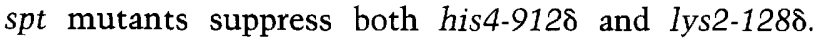
None of the mot1 mutations suppress lys2-1288. Other mutations that suppress his4-912 $\delta$ but not lys2-128 include bur3, bur6, and sin 4 (Prelich and Winston 1993; Jiang et al. 1995). The mot1 mutants did not display a sectoring phenotype. In contrast, to the mot1 mutants, the strains in complementation groups II, III, and IV suppress his $4 \delta-A D E 2$, his4-912 $\delta$, and lys2-1288. Complementation analysis demonstrated that these strains contain mutations in known SPT genes, SPT6, SPT5, and $S P T 2$. The spt6, spt5, and spt2 mutants form white colonies with no red sectors. Because these four groups of mutants did not display a variegating phenotype, they were not studied further.

\section{Mutants with a variegated phenotype}

The remaining $24 \mathrm{Ade}^{+}$mutants all showed a sectoring phenotype, and they fell into at least five complementation groups. Complementation group V contains six independently isolated strains, and these strains all show a sectoring phenotype (Fig. 3). The characterization of the other sectoring mutants will be reported at a later time. These mutants are all $\mathrm{Ade}^{+} \mathrm{His}^{+} \mathrm{Lys}^{-}$, and thus they suppress the his $4 \delta-A D E 2$ and his4-912 $\delta$ mutations, but not 1ys2-1288. The group $\mathrm{V}$ mutations are all recessive, and they all have a strong growth defect. The sectoring phenotype suggests that there are two phenotypic states, that these states are stable through multiple cell divisions, and that a change in phenotypic state /caused by a change in his $4 \delta-A D E 2$ expression, as shown below) can occur during colony development. Importantly, some of the colonies contain double sectors, a white sector within a red sector (indicated by arrows in Fig. 3A), demonstrating that the phenotypic states are reversible. The reverse type of reversibility, a red sector within a white sector, has also been observed, although rarely (data not shown).

The reversibility and heritability of the phenotypic states is demonstrated further in pedigree analyses. Replating of cells from a red sector gives rise predominantly
A
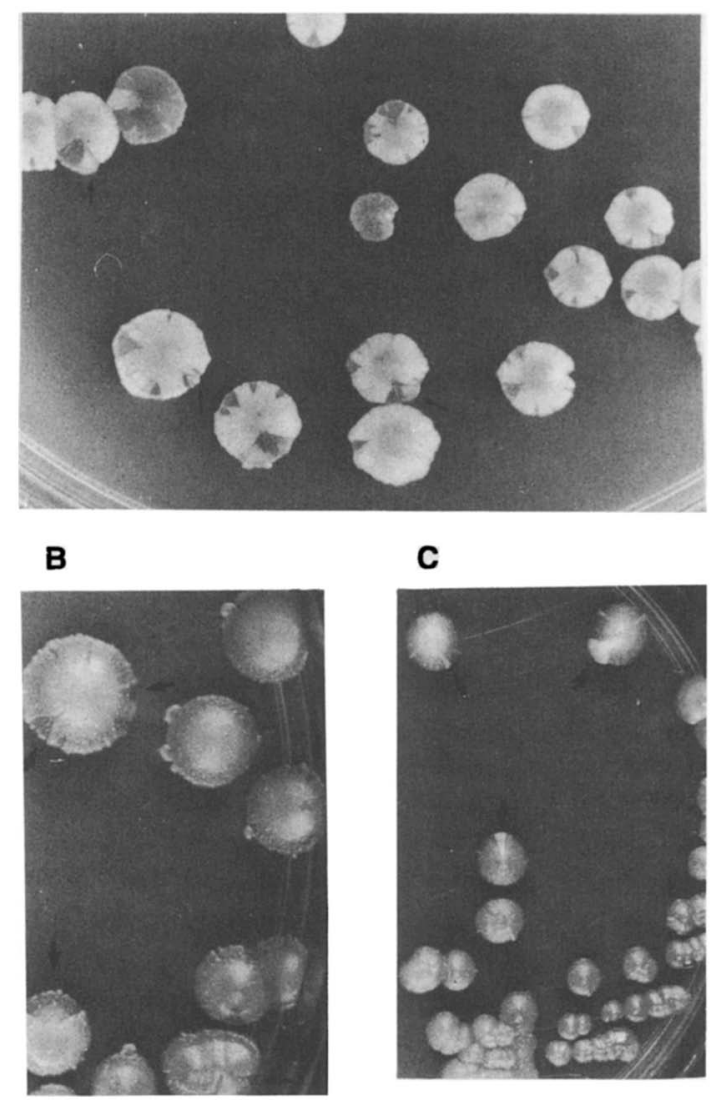

C

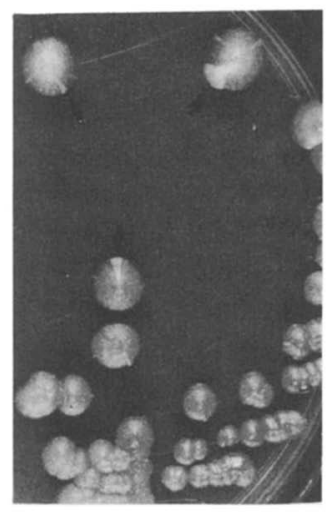

Figure 3. Sectoring phenotype. (A) Strain YY814 (act3-3 his4ס$A D E 2$ ) was spread on YEPD medium to allow colonies to form from single cells. Cells were incubated at $30^{\circ} \mathrm{C}$ for 7 days before being photographed. The arrows show white sectors within red sectors, demonstrating that the phenotypic states are reversible. (B) Strain YY815 (act3-4 his4ס-ADE2) was first streaked on YEPD medium to allow colonies to develop sectors. Cells from a white sector were picked and restreaked onto YEPD medium. Cells were incubated at $30^{\circ} \mathrm{C}$ for 7 days before being photographed. The arrows indicate some of the sectors. $(C)$ As in part $B$, but cells from a red sector were picked and restreaked.

to red colonies with white sectors $(>99 \%)$ and very few white colonies with red sectors $(<1 \%)$; replating cells from a white sector gives the opposite result (Fig. 3). The preponderance of red colonies arising from red cells (and white from white) indicates heritability, and appearance of new sectors demonstrates reversibility.

The fraction of the cells from a red sector that formed white colonies and the fraction of the cells from a white sector that formed red colonies were used to calculate the switch frequencies, as measurements of heritability and reversibility (see Materials and methods). The switch frequency from red to white was measured at 1.9 $( \pm 0.5) \times 10^{-4} /$ cell per generation, and the white to red switches occurred at $1.2( \pm 0.1) \times 10^{-4} /$ cell per generation. The magnitude of the switch frequencies indicates that a phenotypic switch is a relatively rare event, and that 
during a cell division the current phenotypic state is likely to be inherited. However, the switch frequencies are well above the mutation rate $\left(\sim 10^{-8} /\right.$ cell per generation for a wild-type his $4 \delta-A D E 2$ strain to generate an $\mathrm{Ade}^{+}$mutant; data not shown). These results demonstrate that the phenotypic states are semiheritable and that the switches between the phenotypic states are unlikely to be caused by the occurrence of new mutations.

\section{Mutations in a single gene, ACT3, cause the variegated phenotype}

The six mutants in complementation group $\mathrm{V}$ produce sectored colonies, indicating the existence of cells with different phenotypic states within a single colony, caused by different expression states of his $4 \delta-A D E 2$ (see below). Thus, a single colony, composed of cells with presumably an identical genotype, displays distinct phenotypes. A genetic backcross experiment was conducted to determine whether a single locus is responsible for the variegated phenotype seen in the act 3 mutant. Strain YY814 of complementation group V (sectoring, $\mathrm{Ade}^{+}$, $\mathrm{His}^{+}$, slow growing/ was mated to a wild-type strain carrying the same his $4 \delta-A D E 2$ and his4-9128 reporters (nonsectoring, $\mathrm{Ade}^{-}, \mathrm{His}^{-}$, normal growing). The resulting diploid was sporulated and subjected to tetrad analysis. As shown in Figure 4, the sectoring phenotype segregated $2: 2$, with each tetrad producing two uniform and

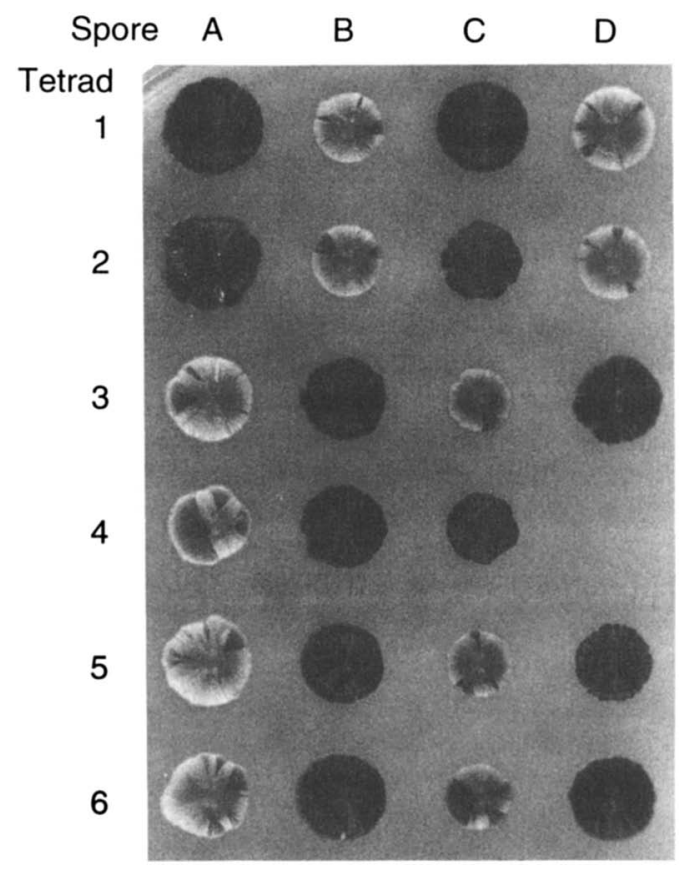

Figure 4. Mendelian segregation of sectoring phenotype. Strain

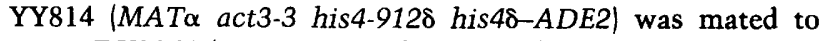
strain DY2864 (MATa ACT3 his4-9128 his48-ADE2), and the resulting diploid was subjected to tetrad analysis. Haploid spores resulting from this cross were germinated on YEPD and allowed to grow at $30^{\circ} \mathrm{C}$ for 7 days before being photographed. Spore 4-D did not germinate. two variegated spore clones. The haploid progeny from this cross were also scored for adenine and histidine prototrophy, and for the growth defect. Each spore clone with sectors was $\mathrm{Ade}^{+}, \mathrm{His}^{+}$, and grew slowly. Each spore clone with uniform color was $\mathrm{Ade}^{-}, \mathrm{His}^{-}$, and grew normally. Thus, these phenotypes show complete cosegregation. We conclude that a single mutation, inherited in a Mendelian fashion, is responsible for the epigenetic control.

We determined that the group $\mathrm{V}$ strains contain mutations in the ACT3 gene (see below), and we will henceforth refer to the six group $\mathrm{V}$ alleles as act3-1 through act3-6. The group $\mathrm{V}$ mutants exhibit a strong growth defect, and we used plasmid complementation to clone the gene. Strains with group V mutations were transformed with a YCp50 genomic library (Rose et al. 1987), and fast-growing transformants were identified. These strains were tested for adenine and histidine auxotrophy, as these mutants, with the his $4 \delta-A D E 2$ and his4-912 alleles, are $\mathrm{Ade}^{+}$and $\mathrm{His}^{+}$, whereas a wild-type strain with these alleles is $\mathrm{Ade}^{-}$and His ${ }^{-}$. Plasmids were rescued from the phenotypically wild-type strains, passaged through Escherichia coli, and retransformed into group V mutants. Two plasmids were able to complement all of the group $\mathrm{V}$ defects after retransformation, and restriction analysis demonstrated that these clones contain overlapping inserts (Fig. 5). Various fragments were subcloned into a single copy vector and tested for complementation of group $\mathrm{V}$ defects, and the results suggested that a 3-kb KpnI-XhoI fragment is required for complementation. To identify the chromosomal location of this region, this KpnI-XhoI fragment was radiolabeled and hybridized to prime clone filters (Riles et al. 1993). The probe hybridized to clones 6713 and 3935 (ATCC nos. 70776 and 70236 , respectively) near ARG3 on chromosome $\mathrm{X}$. The DNA sequence was determined for the ends of subclones generated with ExoIII, and a data base search revealed an exact match with the ACT3 gene (GenBank accession no. X75317) reported by Harata et al. (1994). [Note that a different yeast gene was subsequently published with the name ACT3 /Clark and Meyer 1994); this same sequence had been described previously as ACT5 (Muhua et al. 1994).] Finally, no complementation was seen with plasmid M2704, which lacks the DNA encoding the first 100 amino acids of Act3p, suggesting that the $A C T 3$ open reading frame is responsible for the complementation.

Linkage analysis was performed to demonstrate that $A C T 3$ is allelic to a group $\mathrm{V}$ mutation and that the complementation is not a multicopy suppression phenomenon. Strain DY3460 was constructed that contains the URA3 gene adjacent to the carboxyl terminus of the ACT3 coding region. This strain (DY3460; $\mathrm{Ade}^{-} \mathrm{His}^{-}$ URA3) was crossed to a group V mutant (YY814; Ade $^{+}$ $\mathrm{His}^{+}$ura3), and the resulting diploid was subjected to tetrad analysis. For each of 10 complete tetrads we recovered two $\mathrm{Ade}^{-} \mathrm{His}^{-} \mathrm{Ura}^{+}$segregants and two $\mathrm{Ade}^{+}$ $\mathrm{His}^{+} \mathrm{Ura}^{-}$segregants. Thus, no genetic recombination was observed between these markers in this cross, and we conclude that $A C T 3$ is allelic to the group V mutation. 

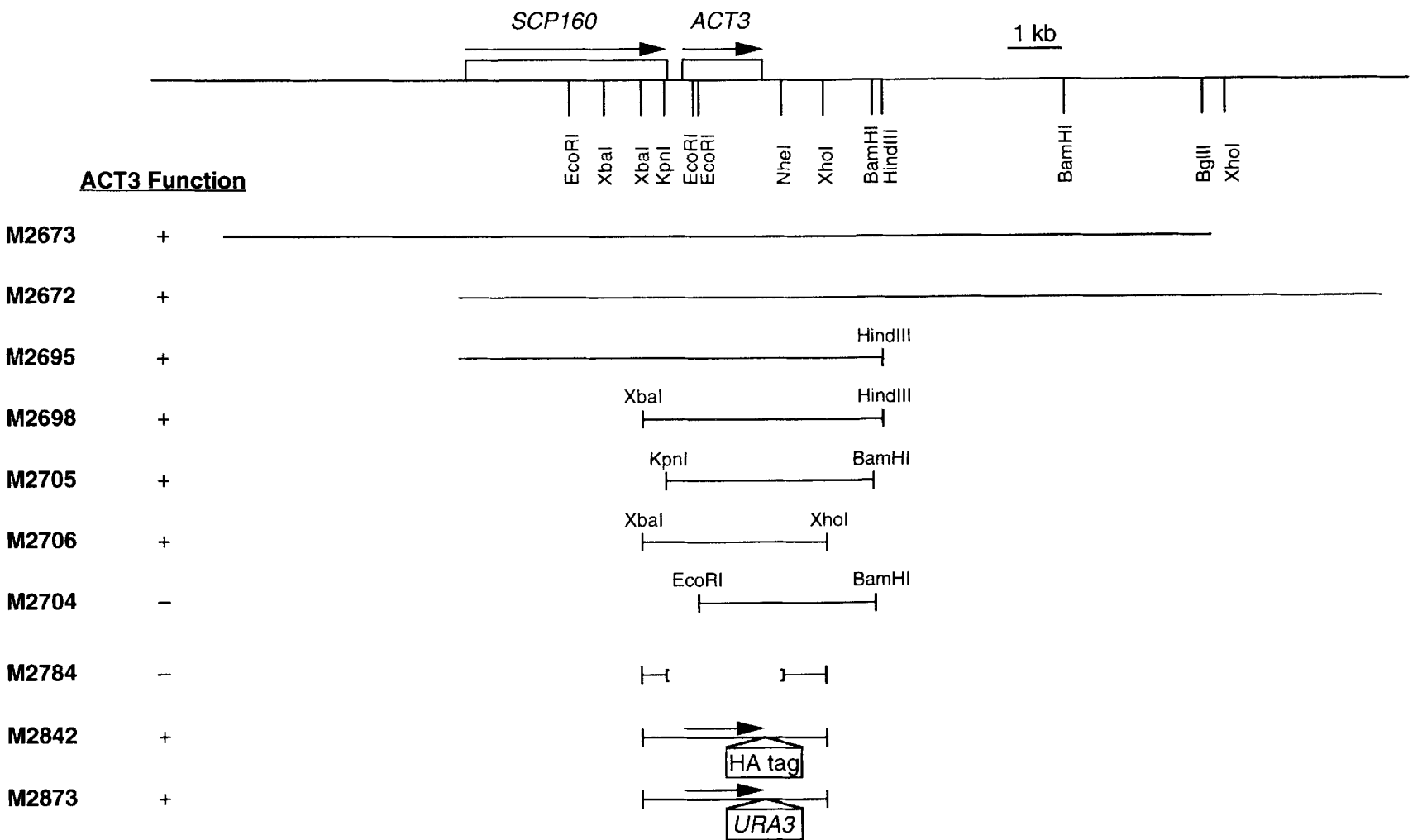

Figure 5. Complementation by ACT3 subclones. Plasmid subclones tested for complementation of an act 3 mutant are indicated. M2673 and M2672 are clones from the YCp50 library, with ends originating from a Sau3A partial digestion. Also shown are plasmid M2784, used for gap rescue of specific alleles, plasmid M2842, which expressed the epitope tagged Act3-HA protein, and plasmid M2873, which has the URA3 gene inserted downstream of the intact ACT3 gene.

\section{ACT3 encodes an actin-related protein}

$A C T 3$ encodes an essential actin-related protein (Harata et al. 1994|, but comparison of Act3p to conventional actin shows some important distinctions /see Discussion). To further our understanding of Act $3 p$ structure and function, we identified the mutations present in our act 3 mutant strains. Each of the six act 3 alleles was cloned by an allele rescue strategy using a gapped plasmid (Rothstein 1991) and sequenced entirely. As shown in Figure 6, each of the alleles has a single nucleotide change leading to a single amino acid replacement. Three of the mutant alleles are replacements of the same residue, C155, by a hydrophobic amino acid. Based on the actin crystal structure, all of the mutated residues are likely to be on protein surface (see Discussion).

\section{Act $3 p$ is a nuclear protein}

There are many examples of a mutation causing a specific phenotype by an indirect mechanism. We were concerned that Act3p might be a cytoskeletal protein and that a mutant Act3p protein could indirectly cause pleiotropic phenotypes including altered transcriptional regulation. Therefore, we determined whether the Act3p

\section{act3mutations}

\begin{tabular}{llcl} 
allele & strength & position & \multicolumn{2}{l}{ substitution } \\
act3-1 & strong & 420 & $\mathrm{~L} \rightarrow \mathrm{R}$ \\
act3-2 & strong & 155 & $\mathrm{C} \rightarrow \mathrm{F}$ \\
act3-3 & strong & 155 & $\mathrm{C} \rightarrow \mathrm{Y}$ \\
act3-4 & strong & 155 & $\mathrm{C} \rightarrow \mathrm{Y}$ \\
act3-5 & weak & 137 & $\mathrm{C} \rightarrow \mathrm{R}$ \\
act3-6 & weak & 454 & $\mathrm{~L} \rightarrow \mathrm{P}$
\end{tabular}

skeletal actin

$\begin{array}{cccc}\text { subdomain } & \text { position } \\ \text { Ila } & & \text { I } & 309 \\ \text { Ila } & & \text { G } & 152 \\ \text { Ila } & & \text { G } & 152 \\ \text { Ila } & & \text { G } & 152 \\ \text { la } & & \text { M } & 132 \\ \text { la } & & \text { I } & 341\end{array}$

Figure 6. Amino acid substitutions in act 3 mutations. The amino acid substitution for each act 3 allele is given, and the corresponding position in skeletal actin is indicated. Note the numbers given for skeletal actin correspond to the positions in the crystal structure (Kabsch et al. 1990); the amino acid sequence derived from the skeletal actin $B$ gene differs because of the post-translational removal of the first two amino acids. 
protein is present in the nucleus and whether act $3 \mathrm{mu}$ tations affect transcriptional regulation.

We used indirect immunofluorescence microscopy to examine the subcellular localization of the Act3p protein. We constructed a strain that expresses Act3-HA, a tagged version of Act3p. The influenza hemagglutinin epitope tag, recognized by the 12CA5 monoclonal antibody, is added at the carboxyl terminus of Act3, and the fusion protein is expressed from the native $A C T 3$ promoter at the wild-type locus. The Act3-HAp is fully functional, as when this is the only ACT3 gene present in these cells the cells grow at a wild-type rate and show no suppression of his4-912 $\delta$ or his $4 \delta-A D E 2$. Yeast cells expressing Act3-HAp as the only version of Act3p were stained with DAPI (to visualize the nuclear DNA) and examined by immunofluorescence microscopy. The data in Figure 7 show clearly that Act $3 p$ is present in the nucleus. Control experiments demonstrate that the immunofluorescence signal requires both the 12CA5 monoclonal antibody (data not shown) and the epitopetagged Act3p. After this paper was submitted, a report from Weber et al. (1995) appeared that also shows that Act $3 p$ is a nuclear protein.

\section{Mutations in ACT3 affect transcriptional regulation}

It has been shown previously that in a wild-type (SPT) strain transcription at the his4-912 $\delta$ allele initiates within the $\delta$ element (Silverman and Fink 1984). This transcript from his4-912 $\delta$ is longer than the wild-type HIS4 transcript. In some spt mutant strains, two transcripts have been observed, a transcript initiating within the $\delta$ element and a shorter transcript initiating at the normal HIS4 mRNA 5' end (Silverman and Fink 1984;

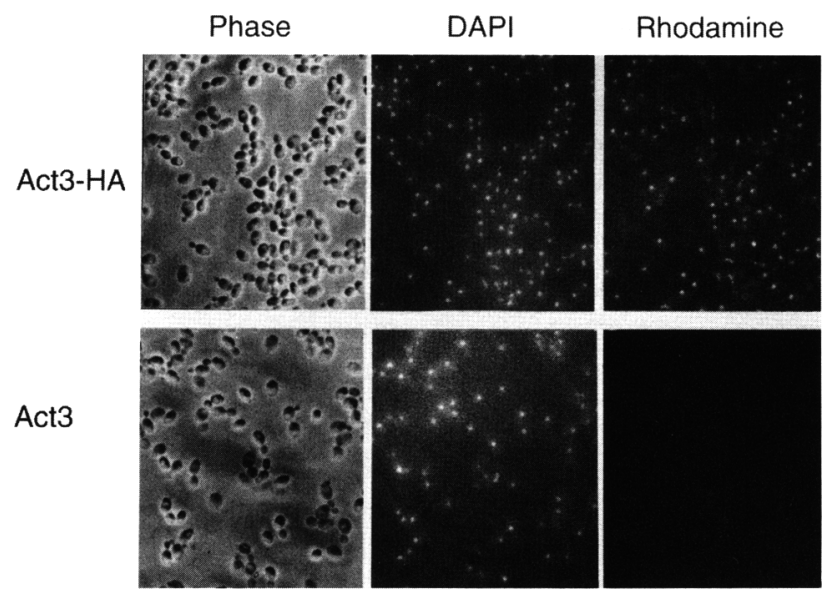

Figure 7. Act3p is present in the nucleus. Logarithmically growing yeast cells were prepared for indirect immunofluorescence microscopy, using monoclonal antibody to the HA epitope. Strain DY3613 expresses the Act3-HA derivative. DY1640 (ACT3) lacks any epitope-tagged protein and serves as a negative control. The indicated micrographs were taken using phase-contrast, DAPI staining (for nuclei), or rhodamine indirect immunofluorescence.
Clark-Adams and Winston 1987), and thus spt mutations affect transcript start site utilization. We examined the transcriptional regulation of his $4 \delta-A D E 2$ in an act 3 strain to see whether the $\mathrm{Ade}^{+}$phenotype is the result of altered transcriptional initiation. In an act 3 mutant an additional shorter transcript from the his $4 \delta-A D E 2$ locus can be detected on a Northern blot (indicated by the asterisk $\left({ }^{*}\right)$ in Fig. $\left.8 \mathrm{~A}\right)$. We postulate that this shorter transcript originates from the native HIS4 transcriptional initiation site in the his $4 \delta-A D E 2$ reporter gene, and thus we suggest that the adenine prototrophy in act 3 mutants results from a change in the transcriptional regulation of the his $4-912 \delta$ promoter.

We wanted to determine whether different transcriptional states of the his $4 \delta-A D E 2$ promoter are responsible for the different phenotypic states in an act 3 mutant. As described earlier, the phenotypic state of act 3 his $4 \delta-$ $A D E 2$, as red or white colonies, is semistably inherited, and we chose to analyze the transcriptional pattern of the his $4 \delta-A D E 2$ promoter in cells of distinct phenotypic states. Cells from white sectors of an act 3 colony were plated on YEPD plates, and after several days growth eight small colonies were picked and RNA was isolated from each colony. Similarly, eight small colonies, originating from cells of red sectors, were harvested and RNA was isolated. As a colony increases in size the probability of a switching event increases, and thus we decided to use small colonies (2-3 $\mathrm{mm}$ in diam.) to increase the likelihood of a uniform population. The phenotype of these colonies, in terms of cell color, was not apparent at the time of harvest, as it can take 7 days of incubation for pigment accumulation to turn an ade2 mutant red. Therefore, we continued to incubate the plates from which these colonies were isolated to allow cells remaining on the plate to form colored colonies, and in all cases the color of the colony reflected its pedigree.

A Northern hybridization experiment was performed to analyze the transcriptional state of promoters in the 16 colonies. Each small colony yielded only a small amount of RNA, and thus the entire RNA preparation from each individual colony was loaded onto one lane of a gel, which was blotted and probed for RNA from his $48-$ $A D E 2$. The $A C T 1$ signal was used as an internal control, as the total amount of RNA loaded differed for each sample. As shown in Figure 8B, the RNA prepared from all eight white colonies contained both the long and the short transcripts originating from the his $4 \delta-A D E 2$ gene. In contrast, none of the eight red colonies produced any detectable his $4 \delta-A D E 2$ transcripts. We conclude that two distinct transcriptional states (On and Off) of his $4 \delta$ $A D E 2$ exist in act 3 strains and that the pattern of activity of the his $4 \delta-A D E 2$ gene is stably inherited. Thus, the epigenetic phenotype in act 3 mutants is the result of epigenetic control of transcription.

The transcriptional patterns of HIS 4 mRNAs from the his4-9128 locus in these strains were also examined. The results in Figure $8 \mathrm{~B}$ show that there are also two stable transcriptional states for his4-912 $\delta$ in an act3 mutant. Colonies $1-7$ and colonies 10-16 expressed both a long and a short transcript (the On state), whereas colonies 8 
A

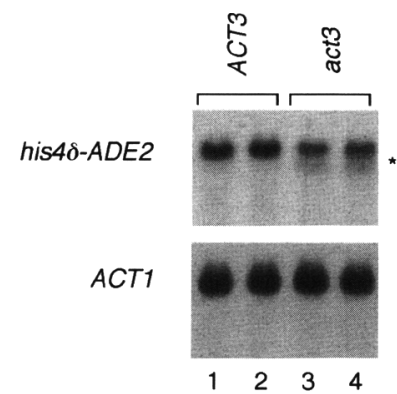

B

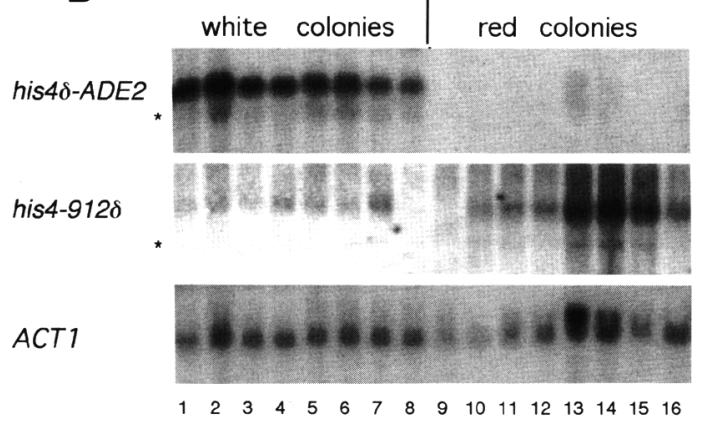

C

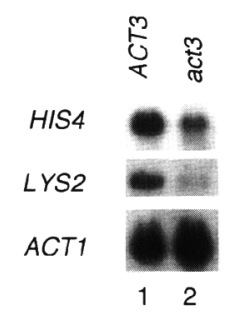

Figure 8. Altered transcriptional regulation in act 3 mutants. (A) RNA was isolated from strains DY2864 (ACT3 his48-ADE2) and YY814 (act3-3 his48-ADE2) grown to mid-log phase in YEPD medium. A Northern blot of total RNA was probed with a labeled $A D E 2$ DNA fragment, and the $A C T 1$ signal serves as a control for RNA loading. The asterisk $\left({ }^{*}\right)$ indicates a shorter transcript that may start at the normal HIS4 transcriptional initiation site. $(B)$ Cells from either a white or a red sector of strain YY815 (act3-4 his48-ADE2 his4-9128) were plated on YEPD medium. RNA was prepared from 16 small colonies, 8 colonies descended from white sectors, and 8 colonies from red sectors, and the production of mRNA from the his $4 \delta-A D E 2$ and his4-9128 loci were analyzed by Northern blotting using ADE2 and HIS4 probes. $\left({ }^{*}\right)$ A shorter transcript that may start at the normal HIS 4 transcriptional initiation site. (For his4-9128, the shorter transcript can be seen most clearly in lanes 13,14, and 15.) The ACT1 signal serves as a control for RNA loading. (C) RNA was isolated from strains DY1880 (ACT3 HIS4) and DY3335 (act3-3 HIS4) grown to mid-log phase in SC medium. A Northern blot was probed with labeled HIS4 and LYS2 fragments, and the ACT1 signal serves as a control for RNA loading.

and 9 did not produce any detectable transcripts from his4-912 $\delta$ (the Off state). There are two transcriptional states for each gene, his4-912 $\delta$ and his $4 \delta-A D E 2$, and the four possible combinations of transcriptional states were all observed. Thus, the transcriptional states of his4$912 \delta$ and his $4 \delta-A D E 2$ in an act 3 cell are independent.
The existence of two transcriptional states of his $4-912 \delta$ in act 3 mutants is consistent with the observation that only a fraction of his4-912 $\delta$ act 3 cells are capable of forming colonies on a plate lacking histidine /data not shown).

The act3 mutation affects expression of the his4-912 $\delta$ and his $4 \delta-A D E 2$ alleles, and both of these promoters contain a $\delta$ element derived from the Tyl retrotransposon. It is possible that the act 3 mutation only affects transcription from genes containing a $\delta$ element, and we therefore asked whether act 3 affects expression of native genes. An act 3 mutation causes a sixfold drop in expression of a HIS4-lacZ reporter (data not shown), and similar decreases in mRNA levels for HIS4 and LYS2 (Fig. $8 \mathrm{C})$. However, an act 3 mutation does not alter the expression of all yeast genes, as the mRNA levels of CTS1, $H O$ and HIS 3 are unaffected in an act 3 mutant (data not shown).

\section{act3 mutations do not affect PEV}

Previous studies have demonstrated that yeast genes located near silencers or telomeres are subject to transcriptional repression and can show epigenetic control of gene expression (Pillus and Rine 1989; Gottschling et al. 1990; Sussel et al. 1993). It is believed that a similar mechanism is responsible for both $H M$ silencing and telomere-dependent repression, because the same genes (SIR2-4, RAP1, ARD1 and NAT1) are required for both types of repression (Kayne et al. 1988; Aparicio et al. 1991; Laurenson and Rine 1992; Thompson et al. 1994). Like the variegation observed in other organisms, silencer- and telomere-dependent variegation show position effect, and thus can be described as PEV. To determine the relationship between the variegation of his $4 \delta-$ $A D E 2$ caused by the act 3 mutation and classical PEV, we asked whether act 3 causes derepression at silencers and telomeres and whether modifiers of PEV affect transcription from promoters containing a $\delta$ insertion.

We used a telomere-linked URA3 gene to determine the effect of an act 3 mutation on telomere repression, as a telomere-linked URA3 gene is subject to telomere-dependent repression in a reversible way, leading to epigenetic patterns of gene expression (Gottschling et al. 1990). In this assay one can measure the fraction of cells with the telomere-linked URA3 gene in the Off state by determining the fraction of cells capable of growth on medium containing 5-FOA, a uracil analog that allows the growth of $\mathrm{ura}^{-}$but not $U R A 3^{+}$cells. As shown in Figure 9A, an act 3 mutation has no effect on telomeredependent repression. Thus, an act 3 mutation does not affect telomere-dependent PEV.

The $H M L$ and $H M R$ silent mating type loci, which serve as donors for mating type interconversion, are maintained in a transcriptionally silent state by a specific chromatin state (Laurenson and Rine 1992). The efficiency of $H M R$ silencing can be measured using an $h m r:: T R P 1$ allele, which contains the TRP1 gene under the control of the HMR silencer. An act 3 mutation does not cause derepression of hmr::TRP1 (Fig. 9B). Strains 

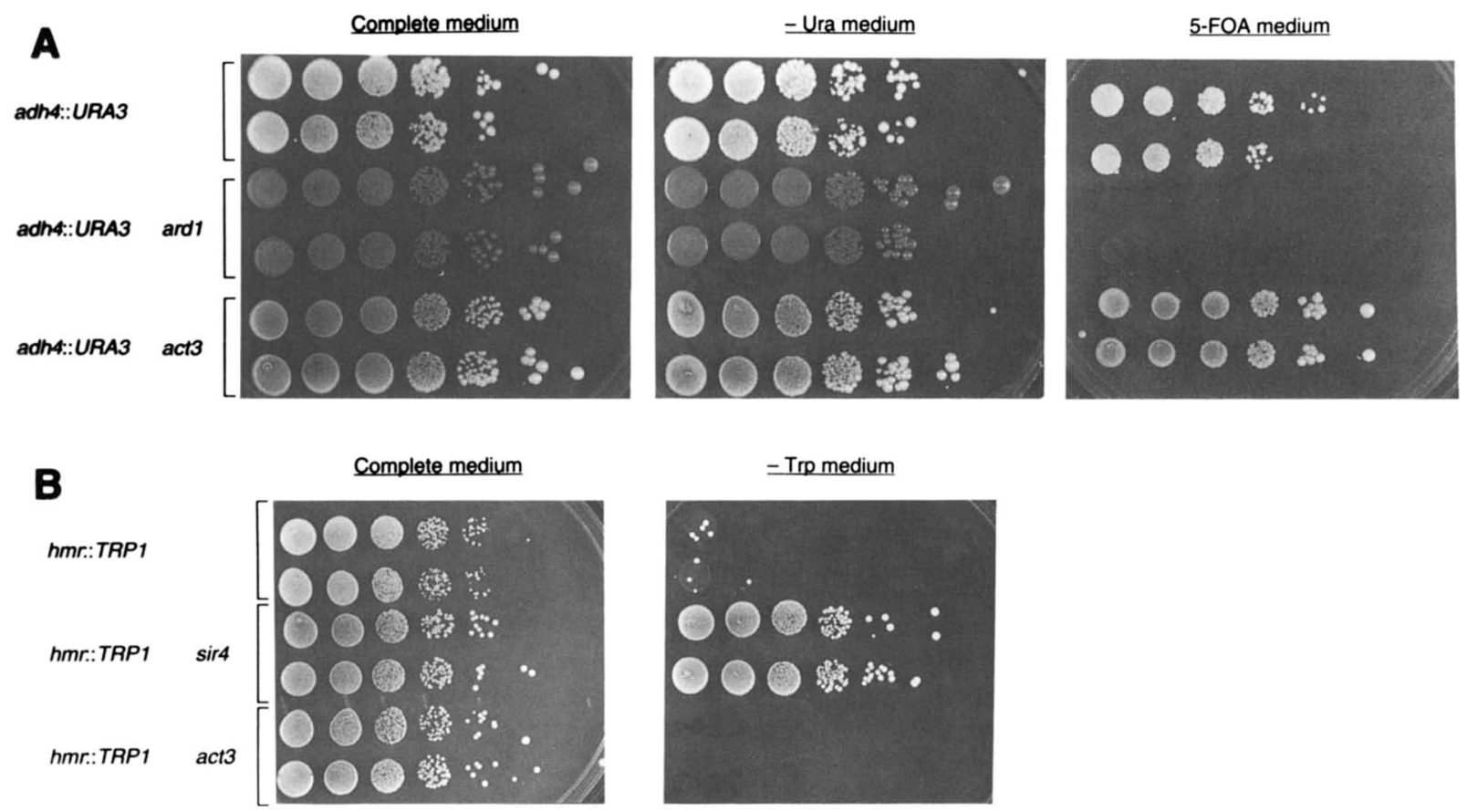

Figure 9. Lack of effect of an act3 mutation on telomere-linked repression and HMRa silencing. (A) Strains DY3331 (adh4::URA3), DY3334 (adh4::URA3 ard1::LEU2), and DY3336 (adh4::URA3 act3-3) were first grown on YEPD plates. Two single colonies from each plate were suspended in $200 \mu \mathrm{l}$ of sterile water, 10-fold dilutions were prepared, and $10 \mu \mathrm{l}$ from each dilution was spotted onto SC, $\mathrm{SC}-\mathrm{Ura}$, and 5-FOA plates. Growth on 5-FOA plates requires telomere-linked repression of the adh4::URA3 locus. This repression is lost in the ard1 mutant but not in the act 3 mutant. $(B)$ Similarly, suspensions prepared from single colonies of strains DY2126 (hmr::TRP1), DY2077 (hmr::TRP1 sir4::LEU2), and DY3241 (hmr::TRP1 act3-3) were diluted and plated onto complete and complete - Trp plates. SIR-dependent repression of the silent mating type loci represses hmr::TRP1. This repression is lost in the sir4 mutant but not in the act 3 mutant. Cells were incubated at $30^{\circ} \mathrm{C}$ for 3 days before being photographed.

with derepressed silent loci have a mating defect, but a quantitative mating assay (Sprague 1991) shows that an act 3 mutant has no mating defect (data not shown). We conclude that the ACT3 gene is not required for repression at the silent mating type loci.

Conversely, we also determined whether regulators of PEV in yeast could affect expression of the his $4 \delta-A D E 2$ or his4-912 $\delta$ alleles. ARD1 and SIR4 are required for silencing of $H M$ loci and for repression of telomere-linked genes (Aparicio et al. 1991). We introduced ard1::LEU2 and sir4::LEU2 mutations into strains with his $4 \delta-A D E 2$ and his $4-912 \delta$ reporters. The resulting ard1::LEU2 his $4 \delta-A D E 2$ his $4-912 \delta$ and sir4::LEU2 his $4 \delta-A D E 2$ his4-912 $\delta$ strains were phenotypically $\mathrm{Ade}^{-}$and $\mathrm{His}^{-}$. This experiment demonstrates that mutations in these two genes required for PEV cannot suppress transcriptional defects caused by a $\delta$ insertion into a promoter.

These experiments demonstrate that different regulatory genes are required for these two types of variegation. We conclude that variegation at the his $4 \delta-A D E 2$ and his4-912 $\delta$ promoters is distinct from the classical PEV seen in yeast at telomeres and $H M$ loci.

\section{Discussion}

There are two notable observations in this paper. The first is the demonstration that $S$. cerevisiae genes can display epigenetic patterns of gene expression without being linked to a telomere or silencer. The fact that distinct transcriptional states can be clonally inherited suggests that the state of a promoter, either On or Off, is stably maintained through multiple rounds of DNA replication and mitotic division. The second finding is the identification of mutations in an essential gene encoding an actin-related protein that cause variegated gene expression. We have shown that this actin-related protein is present in the nucleus and that an act 3 mutation changes the transcriptional regulation of his $4 \delta-A D E 2$, HIS4, and LYS2, suggesting that Act3p acts directly at the level of transcriptional regulation.

\section{Epigenetic effect in the suppression of $\delta$ insertion}

Insertion of a $\delta$ element derived from the Tyl retrotransposon into a promoter can result in gene inactivation (Simchen et al. 1984; Winston et al. 1984). Mutations in a number of $S P T$ genes suppress this defect by changing transcription start site utilization (Silverman and Fink 1984; Clark-Adams and Winston 1987). A $\sin 4$ mutation suppresses the histidine auxotrophy of the his4-9128 allele, but this suppression is incomplete. Thus, cells with an identical genotype display distinct phenotypes. This phenomenon fits the definition of epigenetics. 
We used a his $4 \delta-A D E 2$ reporter to demonstrate that transcriptional status of the promoter can be clonally inherited. A wild-type strain forms white colonies, whereas ade2 mutants form red colonies. Sectored colonies can be observed if the his $4 \delta-A D E 2$ gene displays variegated expression and the state of the promoter is stably propagated through multiple rounds of DNA replication and cell division, with rare switches. We isolated strains with mutations in the ACT3 gene that show a sectoring phenotype and demonstrated that alternative states of gene expression can be stably inherited, yet are reversible.

The use of metabolic genes such as his4-9128 or his $4 \delta-$ $A D E 2$ as reporters to examine variegated gene expression may present difficulties. First, a threshold of expression of a metabolic gene may be required to show prototrophy. This threshold may differ for specific genes because of differences in mRNA translation efficiency or protein stability. (For example, more ADE2 gene product may be required for prototrophy than for HIS4. Thus, although his4-912 $\delta$ and his $4 \delta-A D E 2$ have the same promoter, a weak suppressor such as $\sin 4$ suppresses his $4-912 \delta$ but not his $4 \delta-A D E 2$, producing a $\mathrm{His}^{+} \mathrm{Ade}^{-}$phenotype.) Second, variegation will only be seen if the On and Off states of gene expression are above and below, respectively, the threshold for the cells being prototrophic, and the transcriptional state of the promoter is stably inherited. We suggest that this occurs for act 3 his $4 \delta-A D E 2$ and $\sin 4$ his 4-9128, leading to variegation. In contrast, no variegation is seen with mot1 his $4 \delta-A D E 2$ or spt6 his $4 \delta-A D E 2$, although these strains are adenine prototrophs. We suggest that in these instances either the Off state of the promoter provides sufficient expression for prototrophy or that promoter switching between the two states is very rapid, although it is possible that no variegation is observed simply because it might not be occurring.

\section{Variegated gene expression in act 3 mutants}

The act 3 mutation affects transcription from his $4 \delta-$ $A D E 2$ in two distinct ways. First, only one transcript is seen originating from his $4 \delta-A D E 2$ in $A C T 3$ strains, but there are two his $4 \delta-A D E 2$ transcripts in act 3 cells (Fig. 8A). Transcription initiates in the $\delta$ element in the his 4 $912 \delta$ promoter, producing a transcript with a short open reading frame upstream of the HIS4-coding region that cannot be used as a template to produce functional His $4 p$ protein (Silverman and Fink 1984; Clark-Adams and Winston 1987). In spt mutants, transcription initiates at the normal HIS4 mRNA start site, leading to the production of a second, shorter transcript that can be translated to support histidine prototrophy. We suggest that suppression at his $4 \delta-A D E 2$ occurs analogously in an act 3 mutant, with the shorter transcript being translated into functional Ade2p gene product.

Epigenetic control of transcription is the second way that the act 3 mutation affects his $4 \delta-A D E 2$ expression. The analysis of RNA isolated from individual colonies shows that the state of the his $4 \delta-A D E 2$ promoter as On or Off can be inherited (Fig. $8 \mathrm{~B}$ ). When the his $4 \delta-A D E 2$ promoter in an act 3 mutant is in the On state, both the long and short transcripts are produced, whereas no transcripts are produced when the promoter is in the Off state. Thus, there are three possible transcriptional states for his $4 \delta-A D E 2:$ (1) production of only the long transcript in $A C T 3$ his 48-ADE2 strains, (2) production of both long and short transcripts in act 3 his $4 \delta-A D E 2$ strains (the On state), and (3) no his $4 \delta-A D E 2$ transcription in act 3 strains (the Off state). The transcriptional state of his $4 \delta-A D E 2$ as either On or Off determines which of the two phenotypic states the cell will have, and the fact that the state of the promoter is stably inherited is the underlying cause for the variegation.

The transcriptional variegation seen in act 3 mutants raises questions for which we do not currently have answers. It has been shown that loci under SIR-dependent repression are associated with the nuclear periphery (Palladino et al. 1993; Hecht et al. 1995). Thus, the position of a gene within the nucleus can be an important determinant in transcriptional activity. Although the variegation in act 3 mutants is quite distinct from the SIRdependent PEV (see below), it is possible that the subnuclear location of his $4 \delta-A D E 2$ may be different in the On and Off populations of act 3 mutants. Another question is whether genes without a $\delta$ element can be subject to the general epigenetic On or Off regulation in act $3 \mathrm{mu}-$ tants, or whether loci (other than at telomeres and silent loci) can be regulated epigenetically in ACT3 strains. Further work is needed to address these questions.

\section{Variegated phenotypes unrelated to PEV}

PEV, which occurs when a chromosomal rearrangement places a euchromatic gene in the vicinity of heterochromatin, has been observed in D. melanogaster, S. pombe, and S. cerevisiae (Gottschling et al. 1990; Allshire et al. 1994; Henikoff 1994; Karpen 1994). The variegated phenotype we have described is fundamentally different from PEV seen at yeast silencers and telomeres. First, the act3 mutation has no effect on the known type of PEV in yeast, either on HMR silencing or on telomeric repression. Second, we did not see suppression of the his4-9128 or his $4 \delta-A D E 2$ alleles when the strain contained either an $\operatorname{ard} 1$ or a sir 4 mutation, although $A R D 1$ and SIR4 are required for repression at $H M$ loci and telomeres.

Although chromatin structure has been implicated in both suppression of gene inactivation by $\delta$ insertions and PEV, mutations in histone genes affect these two phenomena differently. Point mutations and deletions in the amino-terminal region of histone $\mathrm{H} 4$ abolish PEV at $H M$ loci and telomeres (Aparicio et al. 1991; Thompson et al. 1994), but these same mutations have no effect on suppression of gene inactivation by $\delta$ insertions (Y.W. Jiang and D.J. Stillman, unpubl.). On the other hand, the histidine auxotrophy caused by the insertion of a $\delta$ element into the HIS4 promoter can be suppressed by changing the gene dosage of histone $\mathrm{H} 2 \mathrm{~A}-\mathrm{H} 2 \mathrm{~B}$ (Clark-Adams et al. 1988), but altering histone H2A-H2B stoichiometry does 
not have an effect on PEV in yeast (Y.W. Jiang and D.J. Stillman, unpubl.).

Mutations that modify PEV in $D$. melanogaster have been identified, and these modifiers can be extremely sensitive to gene dosage. A modifier mutation can either enhance or suppress PEV, depending on gene dosage (Locke et al. 1988; Reuter et al. 1990; Eisenberg et al. 1992). Changing the dosage of SIR genes can have a marked effect on PEV in S. cerevisiae (Stone et al. 1991; Renauld et al. 1993). In contrast, overexpression of the $A C T 3$ or SIR3 genes from a multicopy plasmid does not suppress the transcriptional defect caused by $\delta$ insertion into promoters (data not shown).

We have observed the epigenetic control at two loci (HIS4 and ADE2) that are not associated with telomeres, centromeres, or silencers, and thus this type of epigenetics seems unaffected by the position of the reporter gene. Although we believe that this newly discovered type of epigenetic control of gene expression in yeast is largely independent of chromosomal position (except for silencers and telomeres), this is difficult to prove without testing a reporter at every locus in the genome. Nevertheless, we were able to use genetic criteria to demonstrate that this type of epigenetic control is different from the known PEV at telomeres and HM loci. We conclude that this type of variegation is not caused by $S I R$-dependent heterochromatin formation (Hecht et al. 1995) and that this variegation is independent of telomeres and $H M$ loci.

\section{Act $3 p$, an actin-related protein}

We identified the ACT3 gene by mutations that permit variegated expression of a his $4 \delta-A D E 2$ reporter. The predicted amino acid sequence of Act $3 p$ is $36 \%$ identical (55\% similar) to skeletal actin (Harata et al. 1994). Act3p is substantially larger than skeletal actin (489 vs. 375 amino acids), because of two large insertions and a longer amino-terminal region.

The crystal structure of rabbit skeletal actin has been determined (Kabsch et al. 1990), and we used it as a reference for comparison to Act3p. Actin has been divided into four subdomains, Ia, Ib, IIa, and IIb. The similarity between actin and Act3p is greatest in subdomains Ia and IIa, and the large insertions in Act3p are located in subdomain IIb, in loops that would be at the surface of the molecule. Act3p lacks the conserved amino acids required for actin-actin interactions (Holmes et al. 1990). Thus, it seems unlikely that Act3p forms actinlike filaments, although this notion requires further experimental testing. It has been suggested that the core of Act $3 p$ is similar to conventional actin, whereas the surface regions differ considerably (Harata et al. 1994), and thus Act3p may interact with a different set of proteins.

We analyzed the positions of Act 3 p mutations (Fig. 6) in relation to the corresponding positions in skeletal actin, based on the crystal structure of skeletal actin (Kabsch et al. 1990). The act3-1 mutation is a Leu $\rightarrow$ Arg replacement at amino acid 420 . This corresponds to position 309 (Ile) in the skeletal actin structure, at the be- ginning of an $\alpha$-helical segment. This residue (I309) is on the surface of actin, and this region is highly conserved between Act3p and actin. The act3-2, act3-3, and act3-4 alleles all have a mutation at residue 155 , with the Cys replaced by Phe or Tyr, both hydrophobic amino acids. This corresponds to the Gly residue at position 150 in actin, and this position is at the start of a $\beta$ strand and is solvent accessible. The act3-5 mutation, C137R, may correspond to the Met residue at position 132 in skeletal actin. In actin, M132 is part of a $\beta$ strand that is internal to the protein. However, this region of subdomain Ia is poorly conserved, and thus C137 of Act3p may be in a different position. The act3-6 mutation is a Leu $\rightarrow$ Pro replacement at position 454 , in a region highly conserved between Act3p and actin. Residue L454 of Act3p is equivalent to $\mathrm{I} 34 \mathrm{I}$ in actin, part of an $\alpha$-helical segment on the protein surface that is implicated in interaction with myosin (Rayment et al. 1993). The L454P mutation could disrupt the $\alpha$-helix. Although we doubt that Act3p interacts with myosin, this region of Act $3 p$ may interact with other proteins, and the L454P mutation could interfere with such interactions. In summary, all of the mutated residues are likely to be on protein surface, and thus these mutations could affect the ability of Act3p to interact with other proteins.

Actin binds ATP, and hydrolysis of ATP is required for actin filament formation. It has been proposed that Act3p may possess ATPase activity, as the amino acid residues that compose the ATP-binding cleft of actin are conserved in Act3p (Harata et al. 1994). The ATP-binding region of actin shows structural similarity to the ATPase domain of functionally diverse proteins, including hexokinase, the HSC7O heat shock cognate protein, and bacterial cell cycle regulators (Flaherty et al. 1991; Bork et al. 1992). Thus, the ATPase domain in a protein such as Act3p has many possible functions. We suggest that the actin-related protein Act3p has a very different role in vivo than that of classical actin.

\section{Actin in transcription and chromatin structure}

Several reports have implicated actin directly in transcription and chromatin structure. In 1975 two groups reported the presence of actin and other contractile proteins in chromatin (Douvas et al. 1975; LeStourgeon et al. 1975). Egly et al. (1984) purified a 43-kD factor with the properties of actin which stimulates in vitro transcription by RNA polymerase II. Smith et al. (1979) reported that actin is associated with RNA polymerase II.

Other reports, mostly in amphibian oocytes, have suggested a functional role for actin in transcription and chromatin structure. Rungger et al. (1979) found that injection of anti-actin antibodies into Xenopus laevis oocytes blocks chromosome condensation and suggested that actin participates in the structural organization of chromosomes. Scheer et al. (1984) injected anti-actin antibodies into Pleurodeles waltlii oocytes and found that polymerase II transcription (but not polymerase I) was inhibited. These investigators observed an extensive meshwork of actin-like filament bundles associated with 
isolated lampbrush chromosomes when transcription was repressed by actinomycin D or when RNA was digested by microinjection of $\mathrm{RNase}$. These results suggest a close relationship between nuclear actin and transcription, although it is not clear whether conventional skeletal actin is involved, because the microinjection experiments were conducted with polyclonal anti-actin antibodies. We have shown that yeast Act3p is recognized by polyclonal antibody raised against skeletal actin (Y.W. Jiang and D.J. Stillman, unpubl.), and thus it is possible that the effects observed in the amphibian microinjection experiments could be because the antibodies recognize orthologs of Act3p.

Several recent observations made in yeast provide additional support for the idea that cytoskeleton-related structural proteins are involved in transcriptional regulation. The yeast $A N C 1$ gene was identified in a genetic screen for mutations failing to complement a temperature sensitive act1 mutation (Welch and Drubin 1994), and thus the Anclp protein is implicated in actin function. Subsequently, it was shown that Anclp is present in two components of the RNA polymerase II transcriptional machinery, as Tfg3, a subunit of factor TFIIF, and as TAF30, a subunit of TFIID (Henry et al. 1994). The SMY2 gene was isolated first as a suppressor of a myo2 mutant (Lillie and Brown 1994), and subsequently as a suppressor of a TATA-binding protein (TBP) mutation (P.A. Weil, pers. comm.). Thus, SMY2 genetically interacts with both myosin and TBP. The TSM1 gene encodes the TAF150 subunit of TFIID (Verrijzer et al. 1994), and it has been demonstrated recently that $t \operatorname{sm} 1$ and $t u b 2$ mutations cause synthetic lethality in an allele-specific fashion, suggesting an interaction between TFID and tubulin (D.S. Goldfarb, pers. comm.). Thus, there are several examples of components of the transcriptional ma- chinery that interact, at least genetically, with cytoskeletal proteins. Further studies are needed to determine the role of Act3p in transcription, chromatin, and nuclear structure.

\section{Materials and methods}

Yeast strains

Table 2 lists all strains used. All strains are isogenic to W303 (Thomas and Rothstein 1989) except the S288C strains FY56 and DY2081. The full genotype of W303 is ade2-1 can1-100 his3-11,15 leu2-3,112 trp1-1 ura3-1, and the S288C strains contain the ura3-52 allele. FY56 was obtained from Fred Winston (Harvard Medical School, Boston, MA). DY2081 was constructed by disrupting the SIN4 gene in FY56 (Jiang et al. 1995). Strains were derived by using standard genetic techniques (Sherman et al. 1986). Gene replacements were confirmed by Southern blotting. Cells were grown at $30^{\circ} \mathrm{C}$ in synthetic complete media (Sherman, 1991) containing $2 \%$ glucose supplemented with adenine, uracil, and amino acids, as appropriate but lacking essential components to select for plasmids. YEPD and 5-FOA media and plates were prepared as described (Sherman 1991; Sikorski and Boeke 1991).

The his4-9128 allele was introduced into the W303 background in two steps. First, a 1.1-kb HindIII fragment containing the URA3 gene was inserted into the HindIII site present in the promoter of the his4-53 allele (Devlin et al. 1991), and this construct (M2550) was used to replace the wild-type HIS4 gene in W303 with a his $4:: U R A 3$ allele. Second, a $1.7-\mathrm{kb}$ HindIIIBamHI fragment of pLL53 (Jiang and Stillman 1992) containing the his $4-912 \delta$ promoter was transformed into the his4::URA3 strain, and 5-FOA-resistant transformants were identified. These W303 strains with his4-9128 are phenotypically His ${ }^{-}$at $30^{\circ} \mathrm{C}$ and $\mathrm{His}^{+}$at $37^{\circ} \mathrm{C}$, in agreement with the temperature sensitivity of this allele in S288C strains (Winston et al. 1984).

The introduction of lys2-1288 allele into W303 strains was carried out in multiple steps. First, to create a LYS2 allele rescue

Table 2. Yeast strains

\begin{tabular}{|c|c|}
\hline FY56 & 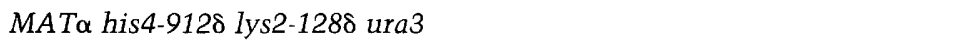 \\
\hline DY2081 & 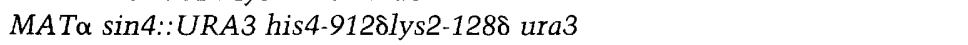 \\
\hline DY2864 & 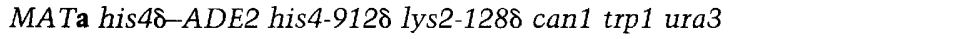 \\
\hline DY2866 & 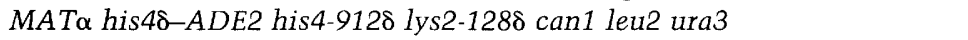 \\
\hline YY812 & 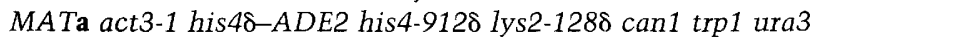 \\
\hline YY813 & 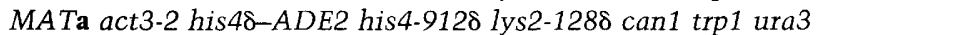 \\
\hline YY814 & 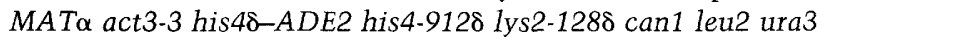 \\
\hline YY815 & 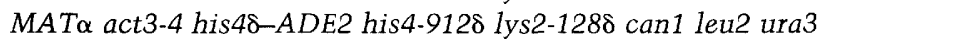 \\
\hline YY816 & 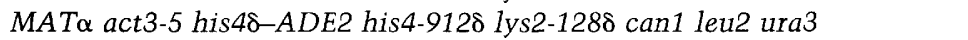 \\
\hline YY817 & 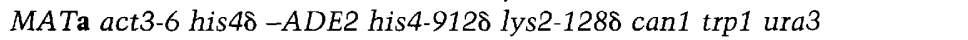 \\
\hline DY3460 & 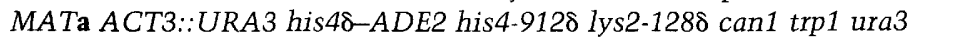 \\
\hline DY3558 & 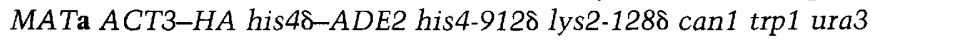 \\
\hline DY3613 & 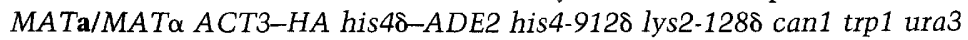 \\
\hline DY1640 & MAT $\mathbf{a} / M A T \alpha$ ade2 can1 his3 leu2 trp1 ura3 \\
\hline DY1880 & MATa ade2 can1 leu2 trp1 ura3 \\
\hline DY3335 & MATa act3-3 adh4::URA3 ade2 can1 leu2 trp1 ura3 \\
\hline DY3331 & MAT $\alpha$ adh4::URA3 ade2 can1 his3 leu2 trp1 ura3 \\
\hline DY3334 & MAT $\alpha$ ard1::LEU2 adh4::URA3 ade2 can1 his3 leu2 trp1 ura3 \\
\hline DY3336 & MAT $\alpha$ act3-3 adh4::URA3 ade2 can1 leu2 trp1 ura3 \\
\hline DY2126 & MAT $\alpha$ hmr::TRP1 ade2 can1 his3 leu2 trp1 ura3 \\
\hline DY2077 & MAT $\alpha$ sir4::LEU2 hmr::TRP1 ade2 can1 his3 leu2 trp1 ura3 \\
\hline DY3241 & MAT $\alpha$ act3-3 hmr::TRP1 ade2 can1 leu2 trp1 ura3 \\
\hline
\end{tabular}


vector, the EcoRV fragment was deleted from plasmid YDp-K (Berben et al. 1991) and replaced by an XhoI linker to construct plasmid M2587. Then, the M2587 insert was subcloned as a 1.5-kb BamHI fragment into YCplacl33 (Gietz and Sugino 1988 ) to generate a LYS2 allele rescue vector, M2588. M2588 was cut with $X h o I$ and BstEII, and the resulting linearized plasmid with a gapped (Rothstein 1991) LYS2 gene was transformed into an S288C strain containing the lys2-128 allele, selecting for $\mathrm{Ura}^{+}$transformants. Plasmid M2593 was recovered from a $\mathrm{Ura}^{+}$colony and shown to contain the lys2-128 allele. Finally, the insert containing lys2-128 was isolated from BamHIcleaved M2593 and used to transform a W303 strain, selecting for $\alpha$-aminoadipate-resistant transformants.

The his $4 \delta-A D E 2$ reporter is actually a replacement of the native $A D E 2$ promoter by the his $4-9128$ promoter. First, the translation starts of $A D E 2$ and the his4-912 $\delta$ genes were changed into $\mathrm{NdeI}$ sites by site-directed mutagenesis (Ausubel et al. 1987). Then, the native $A D E 2$ promoter (from the upstream BstBI site to the newly engineered $N d e I$ site, $450 \mathrm{bp} /$ was replaced by a $1.6-\mathrm{kb}$ Clal-NdeI fragment containing his $4-9128$ promoter to create plasmid M2598. Finally, the 4.8-kb BamHI insert of M2598 containing the his $4 \delta-A D E 2$ reporter and $A D E 2$ flanking sequences was used to transform a W303 strain containing an ade2::URA3 allele, identifying 5-FOA-resistant transformants. Strains carrying the his $4 \delta-A D E 2$ reporter are $\mathrm{Ade}^{-}$at $30^{\circ} \mathrm{C}$ and $\mathrm{Ade}^{+}$at $37^{\circ} \mathrm{C}$, consistent with the observed effects of temperature on histidine prototrophy in strains with his4-9128 (Winston et al. 1984).

Site-directed mutagenesis was used to convert the ACT3 translational stop codon into a $B a m H I$ site, constructing plasmid M2837. A 1.l-kb BamHI URA3 fragment from plasmid YDp-U (Berben et al. 1991) was subcloned into the BamHI site of M2837 to create the ACT3::URA3 integration vector M2873. A 2.5-kb BgllI-XhoI fragment from plasmid M2873 was transformed into DY2864 to introduce the ACT3::URA3 allele via gene replacement, thus constructing strain DY3460. Plasmid M2842, expressing an Act3-HA fusion protein, was constructed by cleaving plasmid $\mathrm{M} 2837$ with $\mathrm{BamHI}$ and inserting two copies of the BgIII fragment (each encoding three copies of HA epitope/ from plasmid pHA/BgIII (provided by Mary Crivellone, SUNY Health Science Center, Syracuse, NY). The copy number and orientation of the HA inserts was determined by restriction digestion and DNA sequencing. The $A C T 3-H A$ allele was introduced by transforming strain DY3460 with a 3-kb KpnI fragment from plasmid $\mathrm{M} 2842$, selecting for gene replacement by 5-FOA resistance, thus constructing strain DY3558. Diploid strain DY3613 was created from DY3558 through HO-mediated diploidization by using a $p G A L-H O$ plasmid (Herskowitz and Jensen 1991). The Act3-HA protein contains six copies of the influenza hemagglutinin epitope (Field et al. 1988) at the carboxyl terminus of Act3p and fully complements act 3 mutants.

\section{Mutant screen}

Two yeast strains, DY2864 (MATa) and DY2866 (MATa), were constructed to screen for mutants. Both strains contain the

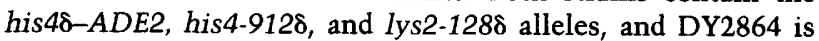
LEU2 trp1 and DY2866 is leu2 TRP1 to allow for convenient diploid selection and complementation testing. Cells $\left(1 \times 10^{9}\right)$ were plated on medium lacking adenine, and 800 spontaneous $\mathrm{Ade}^{+}$mutants were identified. The majority of these $\mathrm{Ade}^{+}$mutants were also histidine prototrophs, and we excluded the $\mathrm{Ade}^{+} \mathrm{His}^{-}$mutants from further study because they could contain cis-acting mutations at his $4 \delta-A D E 2$. To determine whether the mutations are dominant or recessive, mutants were mated to the wild-type strain of the opposite mating type.
Dominant mutations have not been investigated further. Pairwise matings between different recessive MATa and MAT $\alpha \mathrm{mu}$ tants were conducted to place the mutants into complementation groups. If the diploid is $\mathrm{Ade}^{-}$and $\mathrm{His}^{-}$, then the mutations in the two haploids can complement each other, and they are classified into different complementation groups. On the other hand, if the diploid is $\mathrm{Ade}^{+}$and $\mathrm{His}^{+}$, then the mutations in the two haploids fail to complement, and they are classified into the same complementation group. Finally, all of the original isolates, regardless of their complementation grouping, were struck out to single colonies on YEPD plates to determine whether they show a sectoring phenotype.

\section{Rescue of mutant alleles}

Plasmid M2784 was constructed by cleaving plasmid M2698 with KpnI and NheI, blunting the ends with T4 DNA polymerase, and religating; this procedure regenerated the NheI restriction site. Plasmid M2784 was cleaved with NheI and used to transform strains with act 3 mutations, selecting for uracil prototrophy. Homologous recombination led to repair of the gapped plasmid by the mutant chromosomal act 3 allele (Rothstein 1991). Plasmids M2830-M2835 containing the act3-1 through act3-6 mutant alleles were isolated and sequenced.

\section{Cloning the group $I$ and $V$ genes}

The group I and V genes were cloned by complementation of the slow growth phenotypes with a YCp50 library (Rose et al. 1987). The group I and V mutant strains are $\mathrm{Ade}^{+} \mathrm{His}^{+}$due to the suppression of the his $4 \delta-A D E 2$ and his $4-912 \delta$ alleles, whereas $S P T^{+}$strains have an $\mathrm{Ade}^{-} \mathrm{His}^{-}$phenotype; the wild-type group I and $\mathrm{V}$ genes restored the $\mathrm{Ade}^{-} \mathrm{His}^{-}$phenotype to the respective group I and $\mathrm{V}$ mutant strains. The complementing plasmids were rescued from yeast, passaged through $E$. coli, and retransformed into mutants to verify that the complementation was plasmid dependent, and not attributable to reversion. Through the analyses of restriction site pattern, hybridization to filters with genomic clones (Riles et al. 1993), DNA sequencing, and allelism tests, we determined that the group I and V mutants contain mutations in MOT1 and ACT3, respectively.

Two plasmids with overlapping inserts, M2672 and M2673, were obtained that contain the ACT3 gene. Plasmid M2695 was constructed by cleaving plasmid M2672 with HindIII and religating the plasmid, leading to the deletion of a HindIII fragment. Plasmid M2698 was constructed by ligating the 4-kb HindIII$X$ XaI ACT3 fragment from M2695 into plasmid pRS316 (Sikorski and Hieter 1989). Plasmids M2704 and M2705 were constructed by ligating the $3.0-\mathrm{kb}$ BamHI-EcoRI and the $3.5-\mathrm{kb}$ KpnI-BamHI fragments of M2698, respectively, into pRS316. Plasmid M2706 was constructed by deleting the $0.8-\mathrm{kb}$ Xhol fragment from M2698.

\section{Switching frequencies}

Switching frequencies between the two expression states was determined for the act3-3 his48-ADE2 strain by picking cells from red or white sectors with a sterile toothpick, suspending in sterile water, and plating dilutions of the cell suspensions onto YEPD plates. The plates were incubated at $30^{\circ} \mathrm{C}$ for 5 days to allow color formation, and the number of red and white colonies were counted. Switching frequencies were calculated according to the following formula: switch frequency = fraction of colonies switched/generation number, where the number of 
generations $=\log _{2}$ (total number of cells from the original sector suspended in water).

\section{Northern analysis}

Northern blot hybridization using RNA from log-phase cultures was performed as described previously (Dohrmann et al. 1992). For colony RNA analysis, RNA was prepared according to the following method. Single colonies were transferred into a microcentrifuge tube containing 0.3-gram glass beads, $100 \mu \mathrm{l}$ of RNA buffer $(50 \mathrm{~mm}$ Tris at $\mathrm{pH} 7.4,100 \mathrm{~mm} \mathrm{NaCl}, 10 \mathrm{~mm}$ EDTA, $1 \%$ SDS), $50 \mu \mathrm{l}$ of $5 \mathrm{M}$ ammonium acetate, and $150 \mu \mathrm{l}$ of TEsaturated phenol/chloroform/isoamyl alcohol (25:24:1); the cells were lysed by vortexing for $10 \mathrm{~min}$, and the debris pelleted by a 5 min centrifugation. The aqueous phase was transferred to a new microcentrifuge tube and extracted twice with $100 \mu l$ of TE-saturated chloroform/isoamyl alcohol $(24: 1)$, and then the RNA was precipitated with ethanol. The pellet was resuspended in $5 \mu$ l of DEPC-treated water, and the entire preparation was loaded onto an agarose gel. The HIS4 and ACT1 hybridization probes have been described (Jiang and Stillman 1995). The $A D E 2$ probe is a 900-bp NdeI (engineered at the +1 ATG codon) to StuI DNA fragment. The LYS2 probe is a $3.65-\mathrm{kb}$ EcoRV fragment.

\section{Other methods}

Indirect immunofluorescence of permeablized yeast cells was performed as described (Wang et al. 1990) using 12CA5 monoclonal antibody (Field et al. 1988). Preparation of ExoIII deletion subclones and DNA sequencing were performed as described previously (Jiang and Stillman 1992).

\section{Acknowledgments}

We thank Kim Arndt, Mary Crivellone, Dan Gottschling, Rod Rothstein, David Shore, and Fred Winston for strains and plasmids. We gratefully acknowledge Glenn Herrick, David Gard, David Low, and Warren Voth for helpful discussions and/or comments on the manuscript. We also thank David Goldfarb and Tony Weil for communicating unpublished results. This work was supported by a grant from the National Institutes of Health.

The publication costs of this article were defrayed in part by payment of page charges. This article must therefore be hereby marked "advertisement" in accordance with 18 USC section 1734 solely to indicate this fact.

\section{References}

Allshire, R.C., J.P. Javerzat, N.J. Redhead, and G. Cranston. 1994. Position effect variegation at fission yeast centromeres. Cell 76: 157-169.

Aparicio, O.M., B.L. Billington, and D.E. Gottschling. 1991. Modifiers of position effect are shared between telomeric and silent mating-type loci in S. cerevisiae. Cell 66: 12791287.

Auble, D.T., K.E. Hansen, C.G. Mueller, W.S. Lane, J. Thorner, and S. Hahn. 1994. Mot1, a global repressor of RNA polymerase II transcription, inhibits TBP binding to DNA by an ATP-dependent mechanism. Genes \& Dev. 8: 1920-1934.

Ausubel, F.M., R. Brent, R.E. Kingston, D.D. Moore, J.G. Seidman, J.A. Smith, and K. Struhl. 1987. Current protocols in molecular biology. Wiley and Sons, New York.

Berben, G., J. Dumont, V. Gilliquet, P.A. Bolle, and F. Hilger.
1991. The YDp plasmids: A uniform set of vectors bearing versatile gene disruption cassettes for Saccharomyces cerevisiae. Yeast 7: 475-477.

Boeke, I.D. and S.B. Sandmeyer. 1991. Yeast transposable elements. In The molecular and cellular biology of the yeast Saccharomyces. (ed. J.R. Broach, J.R. Pringle, and E.W. Jones), 2nd ed., pp. 193-261. Cold Spring Harbor Laboratory Press, Cold Spring Harbor, NY.

Bork, P., C. Sander, and A. Valencia. 1992. An ATPase domain common to prokaryotic cell cycle proteins, sugar kinases, actin, and hspl0 heat shock proteins. Proc. Natl. Acad. Sci. 89: $7290-7294$.

Chaleff, D.T. and G.R. Fink. 1980. Genetic events associated with an insertion mutation in yeast. Cell 21: 227-237.

Clark, S.W. and D.I. Meyer. 1994. ACT3: A putative centractin homolog in $S$. cerevisiae is required for proper orientation of the mitotic spindle. J. Cell Biol. 127: 129-138.

Clark-Adams, C.D. and F. Winston. 1987. The SPT6 gene is essential for growth and is required for delta-mediated transcription in Saccharomyces cerevisiae. Mol. Cell. Biol. 7: 679-686.

Clark-Adams, C.D., D. Norris, M.A. Osley, J.S. Fassler, and F. Winston. 1988. Changes in histone gene dosage alter transcription in yeast. Genes \& Dev. 2: 150-159.

Covitz, P.A., W. Song, and A.P. Mitchell. 1994. Requirement for RGR1 and SIN4 in RMEl-dependent repression in Saccharomyces cerevisiae. Genetics 138: 577-586.

Davis, J.L., R. Kunisawa, and J. Thorner. 1992. A presumptive helicase (MOT1 gene product) affects gene expression and is required for viability in the yeast Saccharomyces cerevisiae. Mol. Cell. Biol. 12: 1879-1892.

Devlin, C., B.K. Tice, D. Shore, and K.T. Arndt. 1991. RAPl is required for $B A S 1 / B A S 2$ - and GCN4-dependent transcription of the yeast HIS4 gene. Mol. Cell. Biol. 11: 3642-3651.

Dohrmann, P.R., G. Butler, K. Tamai, S. Dorland, J.R. Greene, D.J. Thiele, and D.J. Stillman. 1992. Parallel pathways of gene regulation: The homologous regulators SWI5 and ACE2 differentially control transcription of $\mathrm{HO}$ and chitinase. Genes \& Dev. 6: 93-104.

Douvas, A.S., C.A. Harrington, and J. Bonner. 1975. Major nonhistone proteins of rat liver chromatin: Preliminary identification of myosin, actin, tubulin, and tropomyosin. Proc. Natl. Acad. Sci. 72: 3902-3906.

Egly, J.M., N.G. Miyamoto, V. Moncollin, and P. Chambon. 1984. Is actin a transcription factor for RNA polymerase II? EMBO I. 3: 2363-2371.

Eisenberg, J.C., G.D. Morris, G. Reuter, and T. Hartnett. 1992. The heterochromatin-associated protein HP-1 is an essential protein in Drosophila with dosage-dependent effects on position-effect variegation. Genetics 131: 345-352.

Eisenmann, D.M., C. Dollard, and F. Winston. 1989. SPT15, the gene encoding the yeast TATA binding factor TFIID, is required for normal transcription initiation in vivo. Cell 58: 1183-1191.

Farabaugh, P.J. and G.R. Fink. 1980. Insertion of the eukaryotic transposable element Tyl creates a 5-base pair duplication. Nature 286: 352-356.

Field, J., J.-I. Nikawa, D. Broek, B. MacDonald, L. Rodgers, I.A. Wilson, R.A. Lerner, and M. Wigler. 1988. Purification of a RAS-responsive adenyl cyclase complex from Saccharomyces cerevisiae by use of an epitope addition method. Mol. Cell. Biol. 8: 2159-2165.

Flaherty, K.M., D.B. McKay, W. Kabsch, and K.C. Holmes. 1991. Similarity of the three-dimensional structures of actin and the ATPase fragment of a $70-\mathrm{kDa}$ heat shock cognate protein. Proc. Nat1. Acad. Sci. 88: 5041-5045. 
Gietz, R.D. and A. Sugino. 1988. New yeast-Escherichia coli shuttle vectors constructed with in vitro mutagenized yeast genes lacking six-base pair restriction sites. Gene 74: 527534.

Gottschling, D.E., O.M. Aparicio, B.L. Billington, and V.A. Zakian. 1990. Position effect at $S$. cerevisiae telomeres: Reversible repression of Pol II transcription. Cell 63: 751-762.

Harata, M., A. Karwan and U. Wintersberger. 1994. An essential gene of Saccharomyces cerevisiae coding for an actin-related protein. Proc. Natl. Acad. Sci. 91: 8258-8262.

Hecht, A., T. Laroche, S. Strahl-Bolsinger, S.M. Gasser, and M. Grunstein. 1995. Histone $\mathrm{H} 3$ and $\mathrm{H} 4 \mathrm{~N}$-termini interact with SIR3 and SIR4 proteins: A molecular model for the formation of heterochromatin in yeast. Cell 80: 583-592.

Henikoff, S. 1994. A reconsideration of the mechanism of position effect. Genetics 138: 1-5.

Henry, N.L., A.M. Campbell, W.J. Feaver, D. Poon, P.A. Weil, and R.D. Kornberg. 1994. TFIIF-TAF-RNA polymerase II connection. Genes \& Dev. 8: 2868-2878.

Herskowitz, I. and R.E. Jensen. 1991. Putting the $H O$ gene to work: Practical uses for mating-type switching. Methods Enzymol. 194: 132-145.

Holmes, K.C., D. Popp, W. Gebhard, and W. Kabsch. 1990. Atomic model of the actin filament. Nature 347: 44-45.

Jiang, Y.W. and D.J. Stillman. 1992. Involvement of the SIN4 global transcriptional regulator in the chromatin structure of Saccharomyces cerevisiae. Mol. Cell. Biol. 12: 4503-4514.

- 1995. Regulation of HIS4 expression by the Saccharomyces cerevisiae SIN4 transcriptional regulator. Genetics 140: 103-114.

Jiang, Y.W., P.R. Dohrmann, and D.J. Stillman. 1995. Genetic and physical interactions between yeast RGR1 and SIN4 in chromatin organization and transcriptional regulation. $\mathrm{Ge}$ netics 140: 47-54.

Kabsch, W., H.G. Mannherz, D. Suck, E.F. Pai, and K.C. Holmes. 1990. Atomic structure of the actin:DNaseI complex. Nature 347: 37-44.

Karpen, G.H. 1994. Position-effect variegation and the new biology of heterochromatin. Curr. Opin. Gen. Dev. 4: 281-291.

Kayne, P.S., U.J. Kim, M. Han, J.R. Mullen, F. Yoshizaki, and M. Grunstein. 1988. Extremely conserved histone H4 N terminus is dispensable for growth but essential for repressing the silent mating loci in yeast. Cell 55: 27-39.

Laurenson, P. and J. Rine. 1992. Silencers, silencing, and heritable transcriptional states. Microbiol. Rev. 56: 543-560.

LeStourgeon, W.M., A. Forer, Y.Z. Yang, J.S. Bertram, and H.P. Rusch. 1975. Contractile proteins: Major components of nuclear and chromosome non-histone proteins. Biochim. Biophys. Acta 379: 529-552.

Lillie, S.H. and S.S. Brown. 1994. Immunofluorescence localization of the unconventional myosin, Myo2p, and the putative kinesin-related protein, Smylp, to the same regions of polarized growth in Saccharomyces cerevisiae. J. Cell. Biol. 125: 825-842.

Locke, J., M.A. Kotarski, and K.D. Tartof. 1988. Dosage-dependent modifiers of position effect variegation in Drosophila and a mass action model that explains their effect. Genetics 120: $181-198$.

Moretti, P., K. Freeman, L. Coodly, and D. Shore. 1994. Evidence that a complex of SIR proteins interacts with the silencer and telomere-binding protein RAP1. Genes \& Dev. 8: $2257-2269$.

Muhua, L., T.S. Karpova, and J.A. Cooper. 1994. A yeast actinrelated protein homologous to that in vertebrate dynactin complex is important for spindle orientation and nuclear migration. Cell 78: 669-679.
Palladino, F., T. Laroche, E. Gilson, A. Axelrod, L. Pillus, and S.M. Gasser. 1993. SIR3 and SIR4 proteins are required for the positioning and integrity of yeast telomeres. Cell 75: 543-545.

Piatti, S., R. Tazzi, A. Pizzagalli, P. Plevani, and G. Lucchini. 1992. Control of DNA synthesis genes in budding yeast: involvement of the transcriptional modulator MOT1 in the expression of the DNA polymerase $\alpha$ gene. Chromosoma 102: S107-S113.

Pillus, L. and J. Rine. 1989. Epigenetic inheritance of transcriptional states in $S$. cerevisiae. Cell 59: 637-647.

Poon, D., A.M. Campbell, Y. Bai, and P.A. Weil. 1994. Yeast Taf 170 is encoded by MOTl and exists in a TATA boxbinding protein (TBP)-TBP-associated factor complex distinct from transcription factor IID. J. Biol. Chem. 269: 23135-23140.

Prelich, G. and F. Winston. 1993. Mutations that suppress the deletion of an upstream activating sequence in yeast: Involvement of a protein kinase and histone $\mathrm{H} 3$ in repressing transcription in vivo. Genetics 135: 665-676.

Rayment, I., H.M. Holden, M. Whittaker, C.B. Yohn, M. Lorenz, K.C. Holmes, and R.A. Milligan. 1993. Structure of the actinmyosin complex and its implications for muscle contraction. Science 261: 58-65.

Renauld, H., O.M. Aparicio, P.D. Zierath, B.L. Billington, S.K. Chhablani, and D.E. Gottschling. 1993. Silent domains are assembled continuously from the telomere and are defined by promoter distance and strength, and by SIR3 dosage. Genes \& Dev. 7: 1133-1145.

Reuter, G., M. Giarre, J. Farah, J. Gausz, A. Spierer, and P. Spierer. 1990. Dependence of position-effect variegation in Drosophila on dose of a gene encoding a unusual zinc-finger protein. Nature 344: 219-223.

Riles, L., J.E. Dutchik, A. Baktha, B.K. McCauley, E.C. Thayer, M.P. Leckie, V.V. Braden, J.E. Depke, and M.V. Olson. 1993. Physical maps of the six smallest chromosomes of Saccharomyces cerevisiae at a resolution of 2.6 kilobase pairs. $G e$ netics 134: 81-150.

Roeder, G.S. and G.R. Fink. 1980. DNA rearrangements associated with a transposable element in yeast. Cell 21: 239249.

Roeder, G.S., C. Beard, M. Smith, and S. Keranen. 1985. Isolation and characterization of the SPT2 gene, a negative regulator of Ty-controlled yeast gene expression. Mol. Cell. Biol. 5: 1543-1553.

Rose, M.D., P. Novick, J.H. Thomas, D. Botstein, and G.R. Fink. 1987. A Saccharomyces cerevisiae genomic plasmid bank based on centromere-containing shuttle vector. Gene 60: $237-243$.

Rothstein, R. 1991. Targeting, disruption, replacement, and allele rescue: Integrative DNA transformation in yeast. Methods Enzymol. 194: 281-302.

Rungger, D., E. Rungger-Brandle, C. Chaponnier, and G. Gabbiani. 1979. Intranuclear injection of anti-actin antibodies into Xenopus oocytes blocks chromosome condensation. Nature 282: 320-321.

Scheer, U., H. Hinssen, W.W. Franke, and B.M. Jockusch. 1984. Microinjection of actin-binding proteins and actin antibodies demonstrates involvement of nuclear actin in transcription of lampbrush chromosomes. Cell 39: 111-122.

Sherman, F. 1991. Getting started with yeast. Methods Enzymol. 194: 1-21.

Sherman, F., G.R. Fink, and J.B. Hicks. 1986. In Methods in yeast genetics. Cold Spring Harbor Laboratory, Cold Spring Harbor, NY.

Sikorski, R.S. and J.D. Boeke. 1991. In vitro mutagenesis and 
plasmid shuffling: From cloned gene to mutant yeast. Methods Enzymol. 194: 302-318.

Sikorski, R.S. and P. Hieter. 1989. A system of shuttle vectors and yeast host strains designed for efficient manipulation of DNA in Saccharomyces cerevisiae. Genetics 122: 19-27.

Silverman, S.J. and G.R. Fink. 1984. Effects of Ty insertion on HIS4 transcription in Saccharomyces cerevisiae. Mol. Cell. Biol. 4: 1246-1251.

Simchen, G., F. Winston, C.A. Styles, and G.R. Fink. 1984. Tymediated gene expression of the LYS2 and HIS4 genes of Saccharomyces cerevisiae is controlled by the same SPT genes. Proc. Natl. Acad. Sci. 81: 2431-2434.

Smith, S.S., K.H. Kelley, and B.M. Jockusch. 1979. Actin copurifies with RNA polymerase II. Biochem. Biophys. Res. Commun. 86: 161-166.

Sprague, G.F., Jr. 1991. Assay of yeast mating reaction. Methods Enzymol. 194: 77-93.

Stavenhagen, J.B. and V.A. Zakian. 1994. Internal tracts of telomeric DNA act as silencers in Saccharomyces cerevisiae. Genes \& Dev. 8: 1411-1422.

Steiner, N.C. and L. Clarke. 1994. A novel epigenetic effect can alter centromere function in fission yeast. Cell 79: 865-874.

Stone, E.M., M.J. Swanson, A.M. Romeo, J.B. Hicks, and R. Sternglanz. 1991. The SIR1 gene of Saccharomyces cerevisiae and its role as an extragenic suppressor of several mating-defective mutants. Mol. Cell. Biol. 11: 2253-2262.

Sussel, L., D. Vannier, and D. Shore. 1993. Epigenetic switching of transcriptional states: Cis- and trans-acting factors affecting establishment of silencing at the HMR locus in Saccharomyces cerevisiae. Mol. Cell. Biol. 13: 3919-3928.

Swanson, M.S. and F. Winston. 1992. SPT4, SPT5 and SPT6 interactions: Effects on transcription and viability in Saccharomyces cerevisiae. Genetics 132: 325-336.

Thomas, B.J. and R. Rothstein. 1989. Elevated recombination rates in transcriptionally active DNA. Cell 56: 619-630.

Thompson, J.S., X. Ling, and M. Grunstein. 1994. Histone H3 amino terminus is required for telomeric and silent mating locus repression in yeast. Nature 369: 245-247.

Verrijzer, C.P., K. Yokomori, J.L. Chen, and R. Tjian. 1994. Drosophila TAFII150: Similarity to yeast gene TSM-1 and specific binding to core promoter DNA. Science 264: 933941.

Wang, H., I. Clark, P.R. Nicholson, I. Herskowitz, and D.J. Stillman. 1990. The Saccharomyces cerevisiae SIN3 gene, a negative regulator of $H O$, contains four paired amphipathic helix motifs. Mol. Cell. Biol. 10: 5927-5936.

Weber, V., M. Harata, H. Hauser, and U. Wintersberger. 1995. The actin-related protein Act3p of Saccharomyces cerevisiae is located in the nucleus. Mol. Biol. Cell. 6: 1263-1270.

Welch, M.D. and D.G. Drubin. 1994. A nuclear protein with sequence similarity to proteins implicated in human acute leukemias is important for cellular morphogenesis and actin cytoskeletal function in Saccharomyces cerevisiae. Mol. Biol. Cell. 5: 617-632.

Winston, F., D.T. Chaleff, B. Valent, and G.R. Fink. 1984. Mutations affecting Ty-mediated expression of the HIS4 gene of Saccharomyces cerevisiae. Genetics 107: 179-197. 


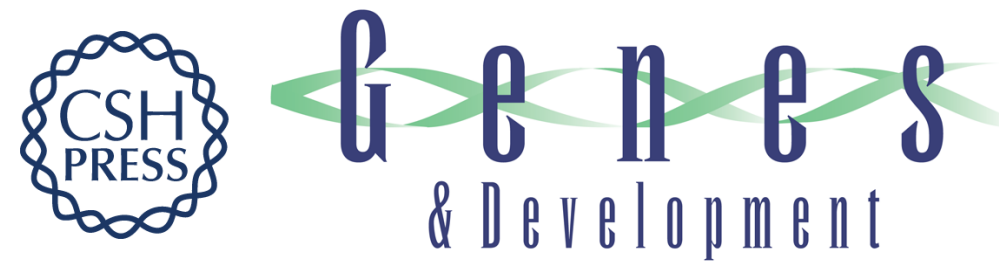

\section{Epigenetic effects on yeast transcription caused by mutations in an actin-related protein present in the nucleus.}

Y W Jiang and D J Stillman

Genes Dev. 1996, 10:

Access the most recent version at doi:10.1101/gad.10.5.604

References This article cites 73 articles, 41 of which can be accessed free at: http://genesdev.cshlp.org/content/10/5/604.full.html\#ref-list-1

License

Email Alerting

Service

Receive free email alerts when new articles cite this article - sign up in the box at the top right corner of the article or click here.

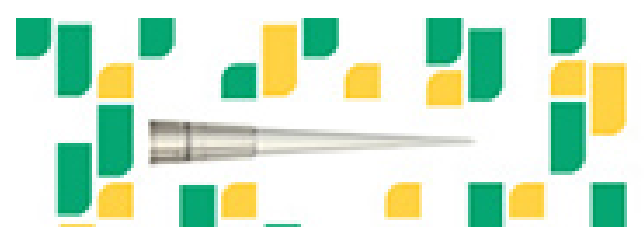

Focused on your science.

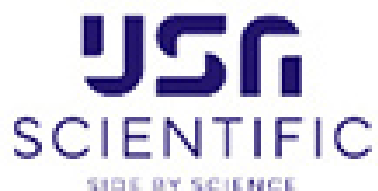

Copyright (c) Cold Spring Harbor Laboratory Press 